NASA Technical Memorandum 105252

AIAA-91-3503

$p .25$

\title{
An Overview of Tested and Analyzed NTP Concepts
}

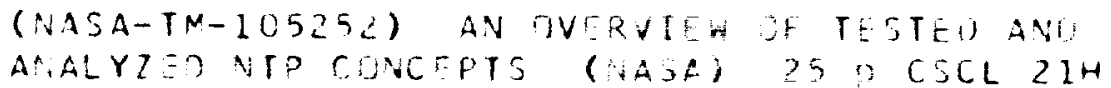

James T. Walton

Lewis Research Center

Cleveland, Ohio

Prepared for the

Conference on Advanced Space Exploration Initiative Technologies cosponsored by AIAA, NASA, and OAI

Cleveland, Ohio, September 4-6, 1991 

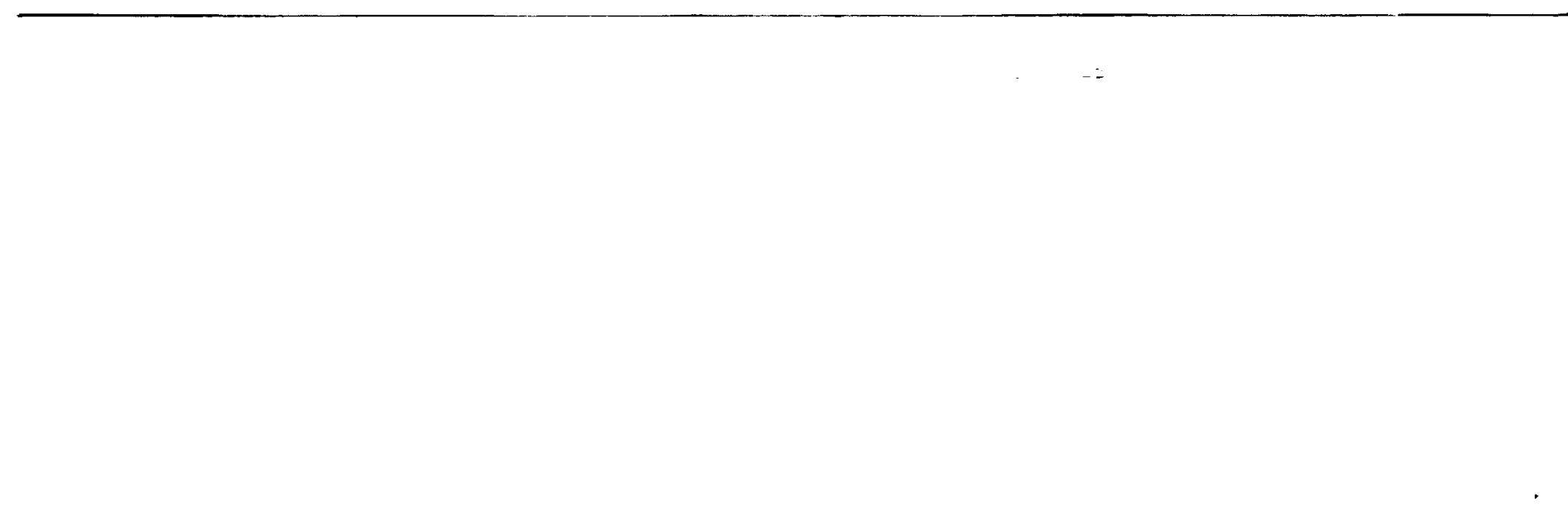

(1)

$\cdot$

.

.

(1) 


\title{
AN OVERVIEN OF TBSTED AND ANALYZED NTP CONCEPTS
}

\author{
James T. Walton ${ }^{\dagger}$ \\ Nuclear Propulsion Office \\ NASA Lewis Research Center \\ Cleveland, OH $\mathbf{4 4 1 3 5}$
}

\section{ABSTRACT}

If we buy into the goals of the Space Exploration Initiative (SEI) and accept that they are worthy of the hefty investment of our tax dollars, then we must begin to evaluate the technologies which enable their attainment. The main driving technology is the propulsion system; for interplanetary missions, the safest and most affordable is a Nuclear Thermal Propulsion (NTP) system. This paper presents an overview of the NTP systems which have received detailed conceptual design and, for several, testing.

\section{INTRODUCTION}

Why should the government of the American people invest billions of dollars on an initiative for space exploration? The following visions at tempt to answer why:

- To further understand the origin and history of our Solar System, the origins of life, and the ultimate fate of our universe

- To utilize vast untapped space mineral resources (gold, platinum, titanium, chromium) and zerogravity material processing awaiting comnercialization for the benefit of mankind - To stimulate a wide range of technical innovations which have previously shown abundant application in the consumer marketplace

- fo strengthen the U.S. economy by high technology investments which improves American competitiveness and global market share

- To provide a motivational stimulus and direction for the advancement of the U.S. science and engineering talent in new generations

- To re-establish and maintain American preeminence in technological innovation and space leadership

If we agree these are tangible goals worthy of the investment to achieve them, then we need to evaluate the technologies allowing their attainment in a safe, affordable manner.

To begin with, shorter transit times are desirable to reduce the impact of the interplanetary journey on the crew and vehicle (radiation, zero-gravity, psychological isolation, equipment degradation). The technological limit on the minimization of trip time is the propulsion system. If further developed, nuclear propulsion technology allows significantly reduced travel durations and reduced vehicle weight (launch costs) to roughly $1 / 2$ that of a current chemical rocket propelled vehicle. From a safety standpoint, the robustness of nuclear thermal propulsion systems allows for greater abort-to-Earth flexibility, and by reducing trip time, allows for a reduced crew inter-planetary radiation exposure.

Since 1946 , many nuclear thermal propulsion systems have been conceived, evaluated, and some even tested. The following sections first cover the general design of nuclear propulsion systems and then describe the systems which received detailed analysis. The intent is to inform the reader sufficiently on the main precursor technology development needed prior to attainment of the space exploration vision.

\section{MUCLEAR THERMAL PROPULSION OYERVIEY}

In conventional chenical rocket engines, such as the SSME, turbopumps drive the propellants (oxidizer (LOX) and reactant $\left(L_{2}\right)$ ) from the tanks into the combustion chamber where the heat of reaction increases the mixture stagnation enthalpy; the high temperature mixture is then exhausted by a convergent-divergent nozzle (Figure 1). For a given mixture molecular weight, a higher stagnation enthalpy results in a higher exhaust velocity and thrust per unit flow rate $\left(I_{\text {sp }}\right)$. With nuclear thermal propulsion (NTP) systents the increase in stagnation enthalpy is achieved by pumping the propellant through a fission reactor core where it cools the reactor; hence, the combustion process is replaced and only a single propellant is required (Figure 1). Since $I_{S P}$ is inversely proportional to molecular weight ${ }^{2}$ low molecular weight propellant, like hydrogen, increases $l_{5 p}$. The advantage of NTP systems is that by using a single propellant with the lowest molecular weight, $H_{21}$ more than two-fold increase in ISP can be realized over current chemical systems: then, the maximum Isp is limited only by the maximum core fuel temperature and heat transfer rate to the propellant. The operating principals for solid core nuclear fission rockets are presented in greater depth in References 1 and 2.

The goal of fission reactor design for NTP is to achieve high power output per unit volume for low weight while providing for a high coolant passage surface area per unit volume for high heat transfer. Both themal- (low velocity) and fast(high velocity) neutron induced fission reactor designs using $U^{235}$ fuel have been evaluated for NTP

T Member AIAA.

Copyright 1991 by the American Institute of Aeronautics and Astronautics, Inc. No copyright is asserted in the United States under Title 17 U.S. Code. The U.S. Government has a royalty-free license to exercise all rights under the copyright claimed herein for Governmental purposes. All other rights are reserved by the copyright owner. 
systens. A typical reactor consists of a core, reflector, radiation shield, and pressure vessel.'

The core contains the $U^{235}$ fuel elements, support structure, and moderator (thermal-reactor only). The moderator consists of light weight materials, such as graphite, beryllium-oxide (Be0) or zirconium-hydride ( $\mathrm{ZrH}$ ), placed in the core to slow the neutrons to thermal velocities. The coderator can be built into the support structure (heterogeneous core) or incorporated in the fuel element (honogeneous core). The latter design results in a lower core weight but a substantially higher fuel loading and core cost (ref. 3).

The reflector is an additional region of moderating material that surrounds the core to reduce neutron leakage by reflecting neutrons back into the core. The reflector assembly may also contain a rotating drum elements used to regulate the number of neutrons reflected back into the core to cause additional fissions, and hence, reactor power. These control drums are made from reflector material except a portion which is covered by a neutron absorbing material such as boron-carbide. The absorber on the drum can be rotated close-to or away-from the core to decrease or increase the number of reflected neutrons, respectively.

A protective radiation shield is normally placed between the reactor and sensitive engine components to decrease radiation heating and material damage from the substantial neutron and gamma field of the fission reactor. Light weight materials with low atomic weights, such as lithiumhydride, are used for neutron attenuation, while the wre penetrating gamma-rays are better handled by a denser material, such as tungsten. The shield may be positioned outside the core and reflector, to intercept the largest possible solid angle, as seen by the reactor, for weight and size minimization. The core, reflector and shield are contained within a pressure vessel onto which the exhaust nozzle is attached. Nozzle thrust is transferred through the nozzle and pressure vessel to the tank thrust structure and spacecraft.

\section{Fuel Element}

For NTP systems, the goal of fuel element design is to achieve the highest possible propellant exit temperature while maintaining structural integrity under design loads. The fuel element must incorporate sufficient fissile fuel to provide the required power and to maintain reactivity across the design life; for reference, thermal-reactors consume 1.24 grams of $U_{235}$ per megawatt in one day. U1timately, the fuel ellement design is a compromise between fabricability, corrosion resistance, and strength at high temperature. The fuel elements in NTP systems may be categorized according to the uranium fuet compound, the matrix material, and the fuel element form.

Fuel compound. The fuel elements in NTP systems usually contain the fissile fuel, $u^{235}$ in either nitride, oxide, or carbide compounds of micrometer particle size. These compounds have higher melting points and better strength characteristics than pure $U^{235}$ (Table 1). Another important consideration of high temperature fuel compounds is their vaporization rate (Figure 2 ). The top curve is $\mathrm{UO}_{2}$ which has the highest rate of all materials shown; it would not be practical to make a fuel element out of plain $\mathrm{UO}_{2}$ because of its excessive vaporization rate. To reduce the fuel vaporization rate, the fuel compound should be completely contained within matrix material that has a lower vaporization rate and is compatible with the coolant.

Hote, $U C_{2}$ particles are extremely reactive and revert to oxide in the presence of air. particularly humid air. oxidation of UC, loaded fuel elements could cause swelling up to 48 . This problem maybe solved by coating the $\mathrm{UC}_{2}$ particles with pyrolytic graphite.

Matrix Material. The fuel elenents usually contain fine particles of the fuel compounds suspended in either a refractory-metal or carbon-based matrix material. The latter matrix material lends itself to thermal reactor designs since carbon is a neutron moderating material; hence, no separate moderator structure would be necessary and the resulting homogeneous reactor would have a lower weight. Carbon-based matrix materials are advantageous because of their high melting temperatures, low density, low neutron absorption, and high strength at high temperature. However, carbon reacts with hot hydrogen to form methane and other hydrocarbons; this corrosion may be reduced with coatings, such as $\mathrm{NbC}$ or $\mathrm{ZrC}$, otherwise carbon mass loss can affect reactor neutronics and life. The carbon-based matrix materials include graphite, carbide, and a composite of both. Figure 3 shows the structure of a graphite matrix where coated fuel particles are embedded in a continuous matrix. Also shown is a comparison with the graphitecarbide composite matrix; in the composite matrix, uncoated fuel particles are dispersed as to form a continuous webbed phase of carbide. For the graphite matrix coated with $\mathrm{NBC}$ or ZrC, once the coating between the matrix and the propellant cracks, carbon is lost indefinitely through the cracks since the graphite is continuous. With the composite matrix, carbon is lost through the cracks until the carbide web is reached; carbon stops escaping except a small amount diffusing through the carbon. The difference in the carbon loss rates between carbon-based matrix materials is shown by figure 4 .

The refractory-metal matrix materials lend themselves to fast-neutron reactor designs (ref. 4). Refractory-metal matrix fuel elements have been developed, such as with $\mathrm{Mo}^{-\mathrm{UO}_{2}}$ and $\mathrm{H}-\mathrm{UO}_{2}$ dispersions (i.e. "cermet" matrix material)? Moreover, a braided tungsten-wire tube has also been used as a matrix material to contain tungsten coated UN particles (ref. 5); tungsten vapor deposition and subsequent swaging is used to seal the fuel in the tube matrix. Tungsten is an ideal refractory-metal matrix material for the following reasons: 1) tungsten has the highest meit ing point of any element (Table 1), 2) tungsten has a low $\left.\begin{array}{l}\text { vapor pressure (much less than graphite), } 3 \\ \text { tungsten does not react with hydrogen, and } 4\end{array}\right\}$ tungsten has a high thermal conductivity.

Note, some reactor designs call for no matrix to contain the fuel particles. These reactors contain either beds of particles $10.02-$ 0.03 inches in diameter) between two porous frits (Figure 16) or thin wall refractory metal tubes 
filled with the fuel compound (fuel pins) around wich coolant flows.

Element Form. The fuel elements in NTP reactors have been designed in many forms, depending on the matrix material. The various forms conceived include the following: plates, wires, cylinders. hexagonal (prismatic) tubes, particles, and pellets. The configurations which have received the most development include the following: $\mathrm{UO}_{2}$ graphite plates, U0,-graphite cylinders with 1, 4 , or 7 coolant channe 5 s, UC-graphite hexagonal tubes with 19 coolant channels, UO, -cermet hexagonal tubes with 19 metal tube coolant channels vo. tungsten wire, and UC-coated particles and pellets.

\section{Support Elewent}

For axial flow prismatic (hexagonal) fuel elements, the core pressure drop is high and therefore, the axial loads on the fuel elements are also large. In the NERVA reactor design (discussed in latter sections), tie-rod support elements were incorporated in the core design: the tie-rod is similar in shape to the fuel elements but contains no fuel. Typically, there are either two or six fuel elements per support element. The tie-rod support element is cooled by either a single-pass of coolant, as are the fuel elements, or are cooled in a two-pass, regenerative mode (Figure 5). Since the tie-rods are usually unfueled, the single-pass tie-rod exit temperature is lower than the fuel element exit temperature: therefore the mixed core exit temperature will be lower. The two-pass tie-rod exhausts back into the core inlet plenum. therefore, the core exit temperature remains high, and should result in a higher mixed mean exit temperature.

\section{Engine Turbopunp Drive Cycle}

To avoid the need for an auxiliary power system for driving the propellant $\left(\mathrm{H}_{2}\right)$ pump hot propellant is extracted from the system to drive a turbopump assembly. NTP concepts are mainly based on two cycle flow-path layouts which differ by the location of the hot hydrogen extraction.

Generally, liquid (or possibly slush) $\mathrm{H}_{2}$ is pumped from the tank to a nozzle coolant manifold. The hydrogen flows through coolant channels to cool the nozzle walls and throat. The flow then cools the reflector and pressure vessel which receives radiation heating. In a "topping-cycle" (Figure 6), this heated hydrogen is routed to drive the turbine; the hydrogen then returns to the reactor vessel inlet. Next, the hydrogen cools the dome shield and core support structure. Finally, the hydrogen enters the core, cools the fuef elements, and increases in stagnation enthalpy. The flow through the core is either axial along the length or radial from an outer-to-inner plenum, or vis-a-versa (figure 7). The hot core cooling gas exits into the nozzle plenum chamber and then through the nozzle to produce thrust.

In a "hot-bleed-cycle" (Figure 6), a small portion ( $-3 \xi)$ of the hot hydrogen is extracted through a bleed port in the plenum to drive the turbine. The turbine inlet temperature is adjusted by mixing the hot gas with a quantity of cooler pump exit gas. The turbine exit drive gas is routed to auxiliary nozzles for roll control or is just dumped. The average $I_{s p}$ of the hot-bleedcycle is lower than for the topping-cycle since the auxiliary nozzles operate at a lower temperature; however, the topping cycle maybe more difficult to implement. Both cycles are started with a "bootstrap" technique which uses the reactor heat capacity and tank pressure for initial turbine drive fluid energy.

\section{TESTED NTP SYSTERS}

Since 1955, several projects have been sponsored by the United States government to investigate gas-cooled, nuclear fission reactorbased space propulsion systems. These projects were conducted under two main programs, ROVER and MERVA, for research and development, respectively. Over 1.5 billion dollars (1968) were invested by the U.S. under these programs leading towards the development of a nuclear thermal propulsion system. These tests were conducted at the Nuclear Rocket Development Station (NRDS) at Nevada's Nuclear Test Site in Jackass flats. Over 20 thermal-reactors for NTP systems were designed, built and tested (Table 2). Us ing reactor power levels of 1100 1500 and 5000 thermal megawatts, thrust levels of 55,75 , and $250 \mathrm{klbf}$ were to be demonstrated along with restart and sustained burn capability. Discussion of individual reactor test objectives and results is presented in Reference 6 . These rocket tests were conducted open cycle with hydrogen coolant/propellant exhausted into the atmosphere; however, current environmental standards would require similar tests to be conducted in a closed cycle mode (ref, 7,8 ). For interplanetary missions after chemical systems such as SSME or RL-10, NERVA-derivative nuclear rockets are next in their technology maturation. The NERVA and ROVER programs were terminated short of actual flight test on January 5, 1973, due to the indefinite postponement of manned Mars missions; following the Apollo program national priorities changed drastically (ref. 9). For a comparison an overview of the USSR's nuclear rocket design philosophy is presented in Reference 10.

\section{ROVER Progran}

The initial nuclear rocket program (ROVER) commenced in 1953 as a backup for the chemical ICBM rocket propulsion development efforts. The ROVER program initially consisted of two exploratory studies, KIWI and TORY, at LOS Almos Scientific Laboratory (LASL) and Lawrence Livermore Laboratory (LLL), respectively. After review of these studies, it was decided that LASL should proceed with a nuclear rocket development program (ROVER) and that the efforts of LLL should be redirected towards a nuclear ramjet development program (PLUTO). Under the PLUTO program, several successful tests of air-cooled reactors, TORY II-A and TORY II-C were conducted to demonstrate the feasibility of nuclear powered ramjet engines, for use at low altitude Mach 3 flight up 10 hours in duration (ref. 11, 12, 13).

Under the ROVER program extensive research was completed on solid core nuclear rocket engines. The main phase began in 1955 at Los Almos Scientific Laboratory under the auspices of the 
Atomic Energy Commission (AEC) and the United States Air Force (USAF) (ref. 14): Under the ROVER program, several $\mathrm{H}_{2}$-cooled, graphitewoderated, bery 11 i um-reflected, $U_{235}$-fueled reactors were built and tested. The basic concept was to heat a high pressure propellant to temperatures of 4500 oR and to expand the high temperature propellant in a high expansion ratio nozzle. The program consisted of several research reactor series including KIHI, Phoebus, Peewee-1, and Nuclear Furnace-l.

KIUI Reactors. The 8 ground reactors under the KIVI series were tested from mid-1959 to mid-1964 (Table 2). These reactors ranged in power from 70 Ant to 1000 Mwt.

The KIHI-A reactor (ref. 15) featured an 18 inch diameter core moderator of 0,0 , surrounded by four layers of $\mathrm{UO}_{2}$ loaded, uncoated graphite fuel plates and one unloaded layer of plates. The resulting core size was roughly 33 inches in diameter and 54 inches in length. The annular graphite reflector surrounding the core was approximately 17 inches in thickness. Under testing in 1959, the hydrogen working fluid flow rate was 7 pounds per second during the 5 minute run time; a power level of 70 Mwt was achieved. Post-test core examination revealed that some core elements reached 5200 or.

KIHI-A' and KIHI-A3 reactors were similar to KIHI-A, except the graphite plates were replaced by long cylindrical, 4-hole, graphite fuel elements with coolant holes to reduce the observed element temperature. The $K I H I-A^{\prime}$ reactor (ref. 16) was tested in 1960 at 88 Mwt for six minutes. The existence of a major structural weakness within the KIHI-A' core was rather dramatically illustrated during the full-power portion of the run by three separate bursts of glowing fuel element fragments ejected from the nozzle. Post-test examination show some fuel element bijtering, corrosion, and transverse fracturing. The KIHI-A3 reactor (ref. 17) was tested in 1960 at an average power of 112.5 Mwt for 259 seconds. As with the previous test, the core experienced structural damage indicating that tensile loads on graphite structures should be avoided. The KIWI-A series of tests (ref. 18) denonstrated the following technologies: instrumentation and control, fuel element design and fabrication, structural design, and testing techniques.

The KIHI-B series (ref. 19, 20, 21) was designed to achieve a 10-fold increase in power ( 1000 Mwt) over the KIWI-A series while holding the size constant, thus demonstrating the basic reactor concept for the Westinghouse/Aerojet General team to develop. This was achieved by eliminating the 18 inch core moderator, increasing the number of fuel elements and coolant holes and by increasing working fluid density (liquid versus gaseous hydrogen). Neutronic control was achieved by 12 rotating drums, containing boron carbide, within the beryllium reflector. Like the KIHI-A reactors, the KIWI-B reactors used pyro-coated UO fuel beads in a graphite matrix; except the last reactor, KIHI-84E (ref. 22), which used 50-150 pm diameter $U C$, particles coated with 25 m pyrocarbon. Throughout this series, six hexagonal fuel elenents were clustered around a single tie-rod support element, cooled by a single pass of $\mathrm{H}_{2}$ that exhausted into the nozzle plenum chanber.
Beginning in the fall of 1961, the early KIHI-B reactors were slowly increased in power from 300 to 1000 Hwt. Post-test examinations revealed a core fuel element instability problem which resulted in broken and missing core elements; this result was evident from bright flashes in the nozzle exhaust during the tests.

It was concluded that dynamic flow instability, in the gap between adjacent fuel element clusters, had caused strong vibration in the core. The KIHI-B4 series incorporated design changes to constrain element movement. The positive results from these reactor tests at full power cleared the way for design and fabrication of flight type reactors, such as the NRX series of the NERVA program.

At the end of the KIWI reactor test series, nuclear rocket engine clustering was investigated. In September 1964, two KIWI reactors were positioned adjacent to one another in a cluster. The results of this zero-power experiment verified there is little nuclear cross-talk between reactors and that they could be operated in clusters, much like chemical engines (ref. 23).

The final reactor to carry the KIWI name was used in a transient nuclear test, KIWI-TNT. This reactor test was a special flight safety experiment to study the behavior and effluent of a KIWI reactor undergoing a sudden excursion and explosion. The modified KIWI-B4E reactor was intentionally destroyed at the NRDS by placing it on a fast excursion through rapid rotation of the modified control drums, followed by mechanical explosion (non-nuclear). Test results showed 1) a maximum core temperature of $3900 \mathrm{oR}, 2$ ) only $50 \%$ of the core material could be located within 25,000 feet, and 3) most likely only 5-15\% of the core vaporized.

Phoebus Reactors. After the Apollo program's Saturn-booster chemical rocket had developed to an advanced state, it was clear that the nuclear thermal rocket would not be needed for the lunar mission. Advanced interplanetary missions were targeted for use of NTP systems. A project was undertaken to design a nuclear rocket for a manned Mars mission, the Phoebus reactor series. The design requirements were a thrust of 250,000 pounds and an Isp of 840 seconds; this requires a reactor power level of 5000 Mwt.

The Phoebus 1 series reactor tests were designed to investigate the level of power density achievable. Phoebus-IA (ref. 24) was tested in 1965 to a power level of 1090 Mwt for more than 10 minutes before exhausting the hydrogen supply and damaging the core; the hydrogen supply gauges were affected by the intense radiation environment. Phoebus-18 (ref. 25) was tested in 1967 at 1460 Mwt for the planned 30 minutes. The post-test examination showed excellent core condition and the test overall demonstrated an average power density of 1 Mwt per element. Exhaust gas analys is indicated a release of $1.5 \%$ of the core fission product inventory, with $0.5 \%$ from fission product bearing uranium fuel and $1.0 \%$ from thermally diffused fission products.

The ability to achieve high power density, as shown by the Phoebus I series, proved that the goals of the Phoebus program could be achieved. 
The next reactor in the program, Phoebus-2A (ref. 26) was the largest propulsion reactor ever tested. The core measured 52 inches in length and 55 inches in diameter; it contained 4068 fuel elements along with 721 tie-rod support elements. Phoebus-2A was about 2.5 times larger than KIW1-B and incorporated two-pass tie-rods to maintain high exit temperature, and hence Isp by exhausting the relatively low temperature coolant back into the core inlet plenum instead of the nozzle chamber. This feature should add 25 seconds to the Isp.

During four tests in 1968, Phoebus 2A achieved a maximum power of 4082 Mwt, limited only by inadequate cooling of its aluminum pressure vessel, for 12 minutes. Post-test examination showed that the core was in excellent condition and could have operated at the designed 5000 Mwt. Moreover, exanination of the fuel elements showed an average mass loss of 10-13 grams per element. Phoebus $2 A$ resulted in a thrust level of over 200,000 pounds and a power density of under 6 pounds per Mwt.

The Phoebus test series firmly established or demonstrated the following: 1) the basic core and fuel element configuration was very satisfactory for NTP systems, 2) methods were available to control reactor parameters safely over a wide range of operating conditions, 3) NbC-Mo coatings will protect the $U C_{2}$-graphite matrix fuel elements from $\mathrm{H}_{2}$ corrosion, 4) a two-pass regeneratively cooled support element was demonstrated which allows for full core performance, and 5) large rocket nozzles, capable of high heat flux and nuclear heating, were shown feasible.

Peewee-1 Reactor. Peewee-1 was a smaller reactor than those investigated under the KIWI series and was designed to evaluate advanced fuel elements for the Phoebus and MRX reactors (ref.27). To provide sufficient neutron moderation in a 20 inch core diameter, zirconium hydride sleeves were placed around the tie rods to increase neutron moderation \& reduce the uranium load. Peewee-1 was tested with $\mathrm{NbC}$ and $\mathrm{ZrC}$ coated fuel elements in late 1968 for a total of 40 minutes at 514 Mwt. A record exit temperature of 4590 oR was achieved along with a power density of 1.3 Mwt per fuel element (5200 Mwt per cubic meter). Post-test inspection showed a structurally sound core, although core material was ejected and there were numerous areas of damage. Moreover, examination of the fuel elements showed the ZrC coated elements out performed the $N B C$ coated elements in reducing corrosion.

Muclear Furnace. Much like the Peewee-1 reactor, the Nuclear Furnace (NF-1) was built for testing $H_{\text {' }}$ cooled fuel elements and other components of high temperature, long life nuclear rocket reactors (ref. 28). The NF-1 was a heterogeneous watermoderated, beryllium-reflected thermal nuclear reactor, designed to operate at 44 Mwt. The advanced hexagonal elements tested were designed for increased corrosion resistance and strength for reaching higher temperatures.

Forty-seven of the forty-nine fuel element cells contained (U, Zr)C-graphite composite fuel elements with carbide content of either 308 or $35 \%$ by volume; these ZrC coated elements had a coefficient of thermal expansion of 3.4 or 3.7 microinch per inch per oR, respectively. Testing of these elements confirmed the belief that minimizing the thermal expansion mismatch between the coating and the fuel matrix reduces coating cracks and carbon mass loss. These elements withsfood peak power densities of 4500 to 5000 Mwt $/ \mathrm{m}^{3}$ at fuel element temperatures of 4410 ok with out difficulty, except for ZrC coatings susceptibility to radiation damage.

Two of the forty-nine fuel element cells contained $(U, Z r) C$ solid-solution fuel elements with a carbide content of 100s; the elements were impregnated with 04,38 or 88 Zr. The primary purpose for testing these elements was to determine their fracture mode at high power densities; major concern was possible crumbling of the carbide, due to poor thermal stress resistance, that could block the flow passage. Testing of these elements showed many transverse and longitudinal fractures, but no fragmentation into small particles. The $8 \% \mathrm{Zr}$ elements showed the least amount of fracturing.

The NF-1 assembly was tested in 1972 for a total duration of 108 minutes at a peak exit gas temperature of 4590 OR along with a power density of $4500 \mathrm{Mwt} / \mathrm{m}^{3}$. The NF-1 operated with a closed. cycle effluent cleanup system for fission fragment scrubbing instead of the traditional open-cycle atmospheric exhaust.

\section{MERVA Prograi}

After the announcement of the Apollo program, a joint NASA/AEC program was initiated to develop a flight rated Nuclear Engine for Rocket Vehicle Application (NERVA). Based on technology developed in the ROVER program, NERVA demonstrated a reusable NTP system with high specific impulse and thrust. The program began in 1960 and was conducted by the joint Space Nuclear Propulsion office (SNPO). The engine was designed to produce a thrust level of $75 \mathrm{klbf}$ and a thrust specific impulse of 825 seconds, twice the Isp of chemical systems, for a run time of 600 minutes. The Isp of nuclear rockets is limited by the melting temperature and high temperature strength of the fuel, moderator, and core structure. The operation time is limited by structural integrity and by the exhaustion of the critical mass due to $U_{235}$ burnup and carbon corrosion. The success of the NRX reactor and XE engine tests has amply demonstrated that the technology is ready for development of the flight version of the NERVA engine and reactor.

Requirements and Objectlves. The design requirements of a fight-rated NERVA rocket engine are summarized by the following.

- Multi-mission capability

- Man-rated (i.e. high refiability)

- Based on full-flow topping cycle

- Minimum chamber temperature and pressure of $\mathbf{4 2 5 0}$

OR and 450 psia, respectively

- Minimum 75,000 pounds thrust

- Endurance of 600 minutes with up to 60 cycles

- Capable of $150 \mathrm{oR} / \mathrm{s}$ and $50 \mathrm{psia/s}$ transients

- Incorporates adequate shielding for manned operations

- Storable for 5 years on ground, 6 months on pad, and 3 years in space

- Transportable by land, air, or sea 
To reach these flight requirements, the following objectives were set forth early in the NERVA progran (1964):

- Develop a nuclear reactor capable of operating at full power and temperature for 60 minutes

- Evaluate the performance capabilities and to dewonstrate the stable operation of the hot-bleed cycle

- Provide the necessary information for the design of future reactor and engine systems

- Develop a simple, reliable reactor control system - Experimentally determine the extremes of the steady-state operating map of the test reactors - Denonstrate the multiple full power restart capability

To satisfy the objectives, NERVA consisted of 2 projects, the Muclear Reactor experiment (NRX) and the experimental flight Engine Prototype (XEPrine); components of both projects were built by the Westinghouse-Aerojet General team. The NRX project was a test of five 1100 Mwt reactors while the XE project tested integrated nuclear and nonnuclear flight components.

URX Reactors. This reactor series was developed to prove that the KIHI-B4 series reactor structure could be adapted to withstand booster-type vibration and shock environments, and that reactor controls could handle rapid exhaust property yariations, such as temperature changes of 100 op per second. In all, testing time and power levels exceeded NERVA design goals.

The objectives of the NRX-A2 (ref, 29) test were to provide significant information for verifying the steady-state design analys is of power operation and for assessing the suitability of reactor operation at power and temperature levels required within the experimental engine system. The NRX-A2, which closely resembled the KIWI-B4E, was tested in September 1964 and operated for 6 minutes with 40 seconds at $1096 \mathrm{MH} ;$ the test duration was limited by the supply of hydrogen available. Post-mortem inspection revealed no broken elements but showed incipient corrosion, especially around the core periphery.

The MRX-A3 (ref. 30) was tested in spring 1965 for a total of 6.7 minutes at $1093 \mathrm{MH}$. The main objectives of this reactor test were to operate for 15 minutes at full power and to shut and cool down using only hydrogen. Post-test disassembly did not show any damage to the core or corrosion to the periphery; NRX-A3 was the first reactor to use externally coated fuel elements along the periphery.

The NRX-A4 (ref. 31) was the first reactor to be coupled with the major engine components, including the turbopump and nozzle with an expansion ratio of $10: 1$, in their functional relationship; the test of this setup. in March 1966, was known as NRX/EST. The goal of the test was to demonstrate the bootstrap start up capability and to evaluate the engine system under transient and steady-state conditions. In all, the engine system was tested under eleven startups, with a total test time of 29 minutes at full-power. The fuel elements showed significant mid-band corrosion and a total of 528 broken elements. The NRX/EST test series was a significant milestone in the development of a nuclear rocket engine. The hot bleed bootstrap principle of nuclear rocket engine operation was demonstrated for the first time, and system stability under a number of control modes and over a wide operating range of pressure and temperature was also proven. Moreover, the multiple restart capability of the engine system was shown, and significant reactor engine operating endurance at rated conditions was demonstrated.

Of prime interest in the NRX-A5 (ref. 32) test series, was the extent of the in-core corrosion and reactivity variation following extended full-power operation. NRX-A5 was tested twice at 1120 Mwt for 29.6 minutes in June 1966. Over the total run duration of 40 minutes, $\$ 2.2$ of reactivity was lost due to corrosion.

The NRX-A6 was successfully tested in December 1967 at 1125 Mwt for 62 minutes (ref. 33) The primary objective was to accomplish a fuli power run to a predetermined loss of reactivity or for a time of 60 minutes. Post-test examination revealed severe cracks in the reflector assembly, which was of a new design. This was attributed to large temperature spike 2 minutes before the end of the test. The NRX-A6 run more than doubled the full power and temperature endurance of previous reactors, with a reduction of 75-80\% in the fuel element time rate of corrosion compared to $N R X-A 4$ and NRX-A5. The reduction of fuel element corrosion is attributed to the improved channel coating techniques, dimensional control across element flats, better regard for the coefficients of thermal expansion, and a flattened core power distribution.

XE-PRIME Engine. This engine was the main focus of the NERVA program with a vertical downward firing into a simulated space vacuum of $1.6 \mathrm{psia}$. The XE engine test (ref. 34) was a full prototype nuclear engine system experiment involving the integration of the reactor (similar to $N R X_{-}-A 6$ ), pressure vessel, nozzle, turbopump assembly and valves in a close-coupled fashion. The XE engine test objectives were to investigate start-up characteristics under different operating modes, determination of engine and component performance parameters, and investigate engine shutdown and pulse-cooling characteristics. This 40,000 pound test engine was designed to produce a thrust of 55,430 pounds at a power level of $1140 \mathrm{Mwt}$, within its $272^{\prime \prime}$ length and 102" diameter. These tests commenced in early 1969 and accomplished full power tests at 1140 Mwt and exit temperatures of 4090 oR The first run duration was 11 minutes with 3.5 minutes at maximum conditions. Also, bootstrap startups without external power were demonstrated.

MERVA Results. The significant feasibility questions to be answered by the NERVA program, as stated in the objectives, were regarding system structural integrity, restart capability, predictability, controliability, and reliability. It was mainly the NRX reactor tests which answered these questions (ref. 35).

Structural Integrity. In the KIWI tests, severe vibrations induced by a destructive flow pattern were observed. These noted vibrations had to be prevented in the NERVA program, and the reactor integrity must be maintained under the operating temperature and pressure drop conditions. This had to be achieved with acceptably low fuel element 
weight 10ss. NRX-AL, NRX-A3 and NRX-A6 reactors demonstrated that the desired endurance capability could be achieve without structural integrity problems, and the latter reactor inparticular showed over the full 60 minute endurance at nominal power.

Restart Capability. The capability to restart the reactor mutiple times throughout its design life was a necessity. This capability was proven by all of the NRX tests except NRX-A6. Ten high power start-ups were conducted on NRX/EST alone. Overall 34 restarts were conducted. The XE tests showed multiple restarts and shutdowns; a total of 23 engine starts to power were conducted. A significant result of the NERVA program was the recognition of the difficult start-up and shutdown process. A typical operating map, a chamber pressure versus temperature curve, is shown in Figure 8. The initial start-up bootstrap is complex but the interrelated phenomena involve transfer of heat from the engine to the $\mathrm{H}_{2}$, the engine flow resistance, and the driving force feeding the engine, such as the tank pressure and the turbopump.

Predictability. To certify a reactor for flight, its performance must be highly predictable within tight constraints. Throughout the NRX tests, predictability has been enhanced by the obtained data. Prior to the NRX-A6 tests, reactor operation predictions were generated and latter compared to the actual operation. The results of the comparison showed excellent agreement when the differences between the planned and actual test profiles are considered. In further support, post examination of the fuel elements revealed their condition to be excellent; the elements could have endured significantly longer operation.

Controllability. Also for flight certification, the system requires close controlling of start-up, steady-state operation, and shutdown (ref. 36). This was well demonstrated by each NRX test. Moreover, NRX-A2, NRX-A3, NRX/EST AND NRX-A5 tests each incorporated advanced control concepts which had been developed during the program.

Reliability. Flight certification places extreme reliability requirements on nuclear thermal systems especially on reactor components. particular emphas is is on the reliability of the fuel elements with full endurance and restart capability (ref. 37). The ten successful NRX, KIWI and Phoebus test series have contributed to the demonstration of reactor reliability.

MERVA Flight Engine Development. The actual NERVA flight engine design was based on the success of the MRX reactor and XE engine tests, but incorporated the topping-cycle instead of the hotbleed-cycle. The flight engine (Figure 9) was designed to use hydrogen at a tank pressure of 30 psia. Dual turbopump assemblies were incorporated, for redundancy, to deliver the hydrogen at 1400 psia to the nozzle and structure as coolant. After cooling the peripheral shield, the warm hydrogen was used to drive the turbine. Turbine exit flow was routed to cool the reactor central shield and the core support plate. Next, the hydrogen entered the reactor core.

The NERVA flight reactor (Figure 10), a complete subassembly, is hydrogen cooled, graphite-moderated, intermediate neutron energy unit designed to operate at a nominal 1575 Mwt and supply 92 pounds per second of hydrogen propellant to the nozzle entrance at $4250^{\circ} \mathrm{R}$ and 450 psia. Reactor components include the following: core, reflector, structural support, shield and reactivity control devices which consist of neutron absorbing vanes assembied in the control drums. The core assembly consists of clustered graphiteuranium fuel elements 54 inches long, including end caps. The reflector assembly consists of a right circular cylinder of beryllium housing eighteen control drums and providing longitudinal cooling holes and lateral support spring pockets. The reactor support structure consists of the core support plate, dome end support cone, nozzle end support ring, and the locating cone. The light weight reactor shield is made of neutron and gamma attenuating material, such as BCAl-TiH (BATH). The prime purpose of this shield is to reduce heating of propellant in the flight tank and protect sensitive components.

\section{AMALYZED NTP SYSTERS}

The following two sections present a review of NTP systems which have been designed and analyzed but not tested to the extent of the ROVER and NERVA reactors. The first section covers NTP systems with reactors containing axial flow, prismatic (hexagonal) fuel elements; the latter section covers systems with alternate element forms. Table 3 summarizes pertinent data on selected systems tested under the ROVER and NERVA programs for comparison to the following. Note, the data in parenthes is was inferred from published material.

\section{Prismatic Element NTP Systems}

During the ROVER and NERVA programs, the benefits of the hexagonal fuel element form were demonstrated. Using the success of this form, two classes of reactor systems have been further studied, NERVA-derivative reactors and cermetmatrix fast reactors. Table 4 presents the systems based on prismatic elements along with the reference NERVA-1 engine design.

NERVA-Derivative Reactors. Generally, NERVAderivative reactors are based on the "mixed" core type, with graphite moderator in the carbon-based matrix fuel elements (as in homogeneous cores) and with $\mathrm{ZrH}$ moderator sleeves in the support elements (as in heterogeneous cores). The mixed NERVAderivative core type results in lower uranium fuel load and lower overall weight.

The Enabler (Figure 11), as conceived by Rocketdyne, is a reactor designed around the graphite/carbide composite fuel elements tested in the Nuclear Furnace. It is of similar scale to the NERVA-1 baseline but was designed to operate at a higher nozzle chamber pressure and temperature with - lower core pressure drop.

The Small Engine (Figure 12), designed by Los Alamos, was scaled to operate at a lower thrust rating for Earth orbit missions. The design chamber pressure was comparable to NERVA-1 however the chamber temperature was higher due to the usage of the composite fuel elements. 
The Small Nuclear Rocket Engine (SNRE) is shown in Figure 13 as designed by Aerojet in the mid-1960's. The engine was scaled to operate at a lower thrust rating and the reactor incorporated the graphite matrix fuel elements proven in the NRX reactor tests; a higher chamber temperature is achieved by this design through the usage of the topping-cycle.

Cernet-Matrix Fast Reactors. In the late 1950's a nuclear rocket engine design effort commenced at General Electric. This effort was focused around a fast neutron fission reactor and was known as the 710 Program. Under this program, engines from 30,000 to 250,000 1bf were designed and analyzed. The fast reactor design incorporated hexagonal fue 1 elements made of $\mathrm{UO}_{2}$ dispersed in a refractorymetal matrix (cermet); several elenents were manufactured and tested under this program. Excellent thermal and mechanical performance was demonstrated over the thousands of hours of testing. The advantage of cermet elements is positive fuel retention due to metal lined coolant channels.

The 710 engine (Figure 14) in Table 4 is an example of the 710 point design results near a MERVA-1 thrust level. The tungsten cermet fuel elements allow for a high chamber temperature to be achieved. Note, the fuel elements were designed with 91 coolant channels to maximize the surface area per unit volume; however, this resulted in a higher core pressure drop.

The Cermet engine (Figure 15) is a 710 engine derivative developed subsequent to cancellation of the 710 Program's rocket engine design phase in 1963. This design incorporated a larger width fuel element with only 19 coolant channels.

\section{Alternative Element NTP Systems}

Although the prismatic element forms dominated testing throughout the 1960's, engines designed around reactors with other element forms deserve considerations. These other element forms include particle (500 en diameter), bead (1,000 $\mathrm{\mu m}$ diameter), pellet $(10,000$ m diameter), and wire (900 un diameter), and the reactors designed around these are shown in Table 5 .

Particle Fuel Elewents. Particle fuel elements are designed with annular beds of $500 \mathrm{~m}$ diameter fuel particles contained between two coaxial porous cylinders (frits); essentially, the frits replace the matrix for containment of the fuel. The propellant flows radially through the element from the cool outer to hot inner frit; the propellant exits axially out the inner frit. A particle bed reactor (PBR) core is composed of particle bed elements arranged in a hexagonal pattern, surrounded by moderating material; the resulting core is encased in a reflector. The advantage of this design is a high surface area per unit volume. A potential problem could be clogging of the frits by the particles; experiments have been conducted at Brookhaven National Laboratories (BNL) to investigate this area.

Table 5 presents data for a 75,000 lbf and a 7,400 ibf thrust particle bed reactor system designed by BNL/Babcock-Wilcox/Grumman (Figure 16).
Note, the design chamber temperature in both designs is significantly higher than in the prismatic element reactors.

Bead Fuel Elements. Bead fuel elements are designed with beds of 1000 m diameter fuel beads contained between two porous frits. Table 5 presents design date for two thrust levels of the Low Pressure Nuclear Thermal Rocket (LPNTR) as conceived by Idaho National Engineering Laboratories (INEL). The LPNTR system (Figure 17) is designed incorporate bead (or wafer) elements and to operate at extremely low chamber pressures, comparatively. By operating at low pressure, the system takes advantage of the increase in the specific heat of hydrogen with decreasing pressure; this results in a significantly higher specific impulse at a given chamber temperature. Moreover, tank pressure alone is sufficient to achieve the design chamber pressure; therefore, no engine turbopump assembly is required.

Pellet Fuel Elewents. Pellet fuel elements are designed with 0.394" diameter fuel pellets contained between two porous frits. The Pellet Bed Reactor (PeBR) concept shown in Figure 18 is a fast neutron reactor. The pellets consist of a UCTaC core with layers of PyC/TaC and $\mathrm{ZrC}$.

Wire Fuel Elements. A study was conducted in the mid-1960's by General Atomics of a compact, high performance nuclear rocket engine which employs tungsten wire fuel elements (Figure 19). The fueled wire was formed by filling a braided tungsten wire tube with 100 un UN particles, vapordepositing tungsten on the tube, and then swaging the filled tube to $900 \mu \mathrm{m}$. The core is constructed of layers of wire wound over alternate layers of spacer wires, which form a rugged annular lattice. The wire core fast reactor is compact in size due to its high surface area per unit volume.

\section{MUCLEAR THEPMAL PROPULSION SAFETY}

The usage, or mere mention of nuclear power tends to cause great public concern, especially when connected to space flight. Prior to public acceptance of nuclear rockets, a comprehensive and publicly credible safety plan must be established (ref.38). In anticipation of flight, extensive safety plans were developed during the ROVER and NERVA programs (ref. 39 , 40). Generally, the objectives of nuclear safety are as follows: 1) to protect workers and the public against "unreasonable" exposure to radiation and toxic materials, 2) to protect the Earth and local space environment against risk of "significant" alteration, and 3) to protect the mission against nuclear system failure (ref. 41). Specifically, the hazards are inadvertent criticality, toxic material release, fallure to "poison" reactor on final shutdown, radiation after shutdown, and diversion of special nuclear materials.

As a guideline, space nuclear reactors and rockets should be able to withstand the following launch hazards: 1) the worst-case pressure gradient associated with the most credible scenario for detonation of the liquid and/or solid rocket propellant, 2) the worst-case temperature due to flame from the detonation, 3) the LEO reentry and earth impact in sea or on land, 4) the worst-case 
credible combination of pressure gradients, temperature, and vibration due to range safety destruct of launch vehicle during ascent. Also, the reactor must have a positive and permanent shutdown system, along with a redundant, automatic shutdown control for all contingencies.

As part of the SNAP-10A space power reactor flight test, a comprehensive nuclear safety program was conducted. This safety program presents a good nodel for future efforts and is well documented in Reference 42. Also, the SP-100 system development effort is integrated around the SP-100 Surety Program; where surety is defined as an integration of safety, safeguards, environmental protection, reliability, and quality assurance (ref. 43). The SP-100 Surety Program has been developed to provide confidence that the surety issues will be adequately integrated in the designs and that flight approval can be obtained while minimizing undue design penalties. The subject of Environmental Impact Statenents is well discussed in Reference 44.

\section{CONCLUSIONS}

The exploration of space is one of mankind's greatest adventures. Engineers and technicians over the next 20 years will be making a permanent mark on history by extending technology to allow for human contact with our neighboring planets. The exploration of the distant planets with unmanned vehicles is a phenomenal achievement; however, manned exploration will require extraordinary technological advances. The task of resurrecting NTP technology and developing it to a man-rated level is one of those extraordinary advances.

Table 1

Melting Points of Reactor Core Material (Ref. 45)

$\begin{array}{llc}\text { Type of Material } & \text { Material } & \text { Temperature (OR) } \\ \text { Fuel } & \text { Uranium } & 2530 \\ \text { Fuel Compound } & \text { Uranium Nitride } & 5690 \\ & \text { Uranium Dioxide } & 5535 \\ \text { Refractory Metal } & \text { Uranium Carbide } & 4810 \\ & \text { Tungsten } & 6580 \\ & \text { Rhenium } & 6200 \\ & \text { Tantalum } & 5890 \\ \text { Refractory Non-Metal } & 5170 \\ & \text { Molybdenum } & 7490 \\ & \text { Hafnium Carbide } & 7480 \\ & \text { Tantalum Carbide } & 7190 \\ & \text { Carbon (sublimation) } & 6790 \\ & \text { Niobium Carbide } & 6210\end{array}$

Table 2

Chronology of ROVER and NERVA Tests (ref. 6)

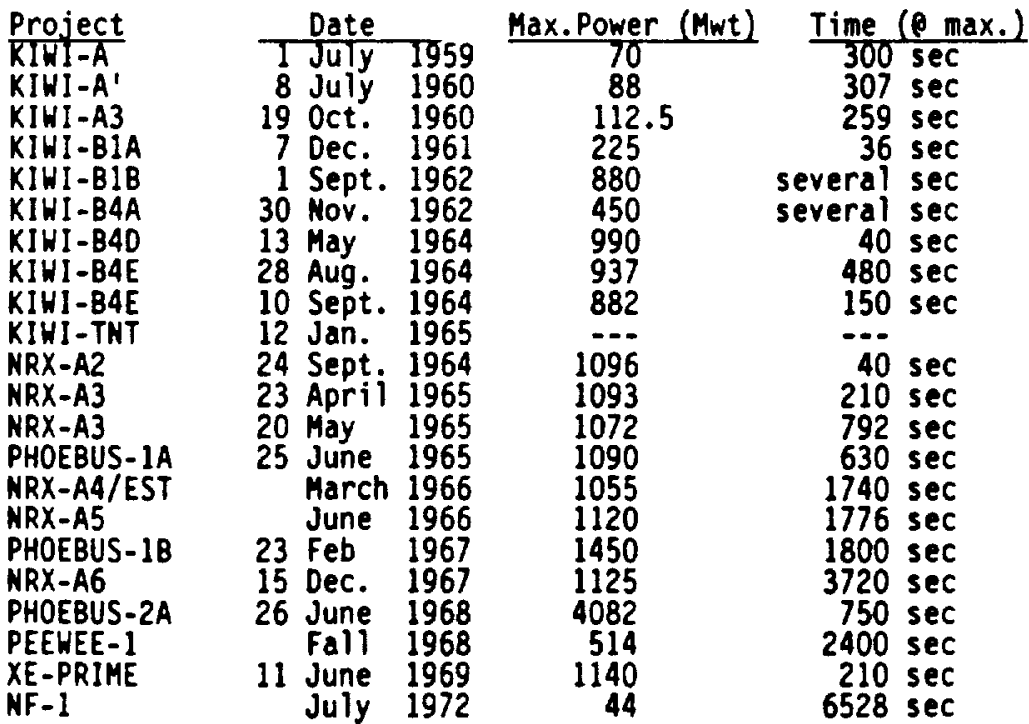


Table 3 - Comparison of Tested NTP Systems.

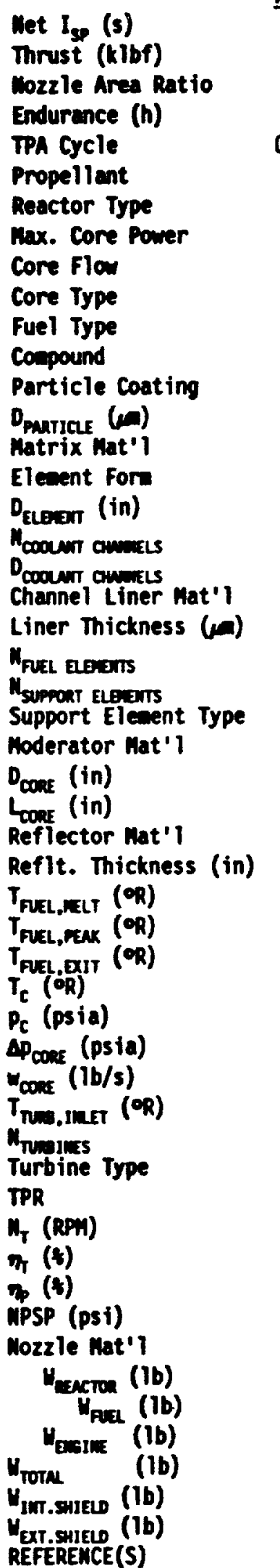

\begin{tabular}{|c|c|c|c|c|c|c|}
\hline \multicolumn{2}{|c|}{ PHOEBUS-IB PHOEBUS-2A } & PEMEE-1 & $M F-1$ & MRX/EST & $M R X-A 6$ & XE-PRIME \\
\hline 835 & 805 & $845^{r}$ & $\overline{830^{2}}$ & 820 & 847 & 710 \\
\hline 68 & 209 & $N / A$ & $N / A$ & 55 & 55 & 55.4 \\
\hline 12 & & N/A & $N / A$ & 10 & 10 & 10 \\
\hline .5 & .21 & .72 & 1.82 & .48 & 1.05 & 0.06 \\
\hline COLO-BLEED & HOT-BLEED & $N / A$ & N/A & HOT-BLEED & $N / A$ & HOT-BLEED \\
\hline$\underset{\text { THERMAL }}{\mathrm{H}_{2}}$ & $\underset{\text { THERMAL }}{\mathrm{H}_{2}}$ & $\begin{array}{r}\mathrm{H}_{2} \\
\text { THERMAL }\end{array}$ & $\begin{array}{r}\mathrm{H}_{2} \\
\text { THERMAL }\end{array}$ & $\begin{array}{r}\mathrm{H}_{2} \\
\text { THERMAL }\end{array}$ & $\begin{array}{r}\mathrm{H}_{2} \\
\text { THERMAL }\end{array}$ & $\begin{array}{r}\mathrm{H}_{2} \\
\text { THERMAL }\end{array}$ \\
\hline 1455 & 4082 & 514 & 44 & 1170 & 1125 & 1140 \\
\hline AXIAL & AXIAL & AXIAL & AXIAL & AXIAL & AXIAL & AXIAL \\
\hline $\begin{array}{l}\text { HOHO. } \\
\mathrm{U}^{235}\end{array}$ & $\begin{array}{l}\text { HOMO. } \\
u^{235}\end{array}$ & $\begin{array}{l}\text { MIXED } \\
U^{235}\end{array}$ & $\begin{array}{r}\text { MIXED } \\
U^{235}\end{array}$ & $\begin{array}{l}\text { HOMO. } \\
\text { U. }^{235}\end{array}$ & $\begin{array}{l}\text { HOMO. } \\
u^{235}\end{array}$ & $\begin{array}{l}\text { HOMO. } \\
U^{235}\end{array}$ \\
\hline $\begin{array}{l}U C_{2} \\
P y C\end{array}$ & $\begin{array}{l}U C_{2} \\
\text { PyC }\end{array}$ & $\begin{array}{l}U C_{2} \\
P y C\end{array}$ & $\begin{array}{l}U C_{2} \\
\text { PyC }\end{array}$ & $\begin{array}{l}U C_{2} \\
P y C\end{array}$ & $\begin{array}{l}U C_{2} \\
\text { PyC }\end{array}$ & $\begin{array}{l}U C_{2} \\
\text { PyC }\end{array}$ \\
\hline $50-150$ & $50-150$ & $50-150$ & $50-150$ & $50-150$ & $50-150$ & $50-150$ \\
\hline GRAPHITE & GRAPHITE & GRAPHITE & COMP/CARB & GRAPHITE & GRAPHITE & GRAPHITE \\
\hline HEXAGONAL & HEXAGONAL & HEXAGONAL & HEXAGONAL & HEXAGONAL & HEXAGONAL & HEXAGONAL \\
\hline .752 & .753 & .752 & .752 & .754 & .753 & .752 \\
\hline 19 & 19 & 19 & 19 & 19 & 19 & 19 \\
\hline .10 & .11 & .11 & .11 & .009 & .10 & .10 \\
\hline $\mathrm{MbC} / \mathrm{Mo}_{\mathrm{O}}$ & $\mathrm{NbC/MO}$ & $\mathrm{NbC}$ & $\mathrm{NbC} / \mathrm{ZrC}$ & $\mathrm{NbC}$ & $\mathrm{NbC}$ & $\mathrm{MbC}$ \\
\hline & & & & $35-70$ & & \\
\hline 1498 & 4068 & 402 & 49 & 1584 & 1584 & 1584 \\
\hline & 721 & 132 & $N / A$ & (289) & & \\
\hline 1-PASS & 2-PASS & 1-PASS & 1-PASS & 1-PASS & 1-PASS & 1-PASS \\
\hline GRAPHITE & GRAPHITE & GRAPH/ZrH ${ }_{x}$ & $\mathrm{GRAPH} / \mathrm{H}_{2} \mathrm{O}$ & GRAPHITE & GRAPHITE & GRAPHITE \\
\hline & 54.7 & $2 \hat{I}$ & 13.4 & 35 & 35 & 35 \\
\hline 52 & 52 & 52 & 57.5 & 52 & 52 & 52 \\
\hline Be & $\mathrm{Be}$ & $\mathrm{Be}$ & $\begin{array}{r}\text { BeO } \\
10.75\end{array}$ & $\mathrm{Be}$ & $\mathrm{Be}$ & $\mathrm{Be}$ \\
\hline & & 4950 & 4950 & (5048) & & \\
\hline 4401 & 4158 & 4570 & 4590 & $>4320$ & 4600 & $>4320$ \\
\hline 4125 & 4068 & 3303 & 3263 & 4125 & 4330 & 4105 \\
\hline 735 & 624 & 620 & 464 & 587 & 593 & 565.8 \\
\hline 203 & & 175 & 217.5 & (124) & & 146.7 \\
\hline 94.4 & 262 & 41.5 & 2.4 & 86.6 & 72 & 70.2 \\
\hline 600 & & $N / A$ & $N / A$ & $(1140)$ & & \\
\hline 2 & 2 & $N / A$ & $N / A$ & 1 & N/A & 1 \\
\hline Mk25 & Mk25 & $N / A$ & $N / A$ & MkIII-4 & $N / A$ & Hk25 \\
\hline 10.4 & & & & & & \\
\hline & & & & 20,343 & & \\
\hline & & & & 58.4 & & \\
\hline & & & & 71.2 & & \\
\hline & & & & 30.23 & & \\
\hline & & $N / A$ & N/A & & & \\
\hline & 20419 & 5665 & & & & 6964 \\
\hline & 661.4 & 79.4 & $<11$ & 401.2 & 401.2 & \\
\hline & & $\begin{array}{r}N / A \\
5665\end{array}$ & $M / A$ & & & $\begin{array}{r}6613 \\
13578\end{array}$ \\
\hline & & $N / A$ & $N / A$ & & & 2901 \\
\hline & & $N / A$ & $N / A$ & & & \\
\hline 46 & 47,14 & $47,14,27$ & 48,28 & 14 & 47,14 & 14,49 \\
\hline
\end{tabular}


Table 4 - Comparison of Prismatic Element Based NTP Systems.

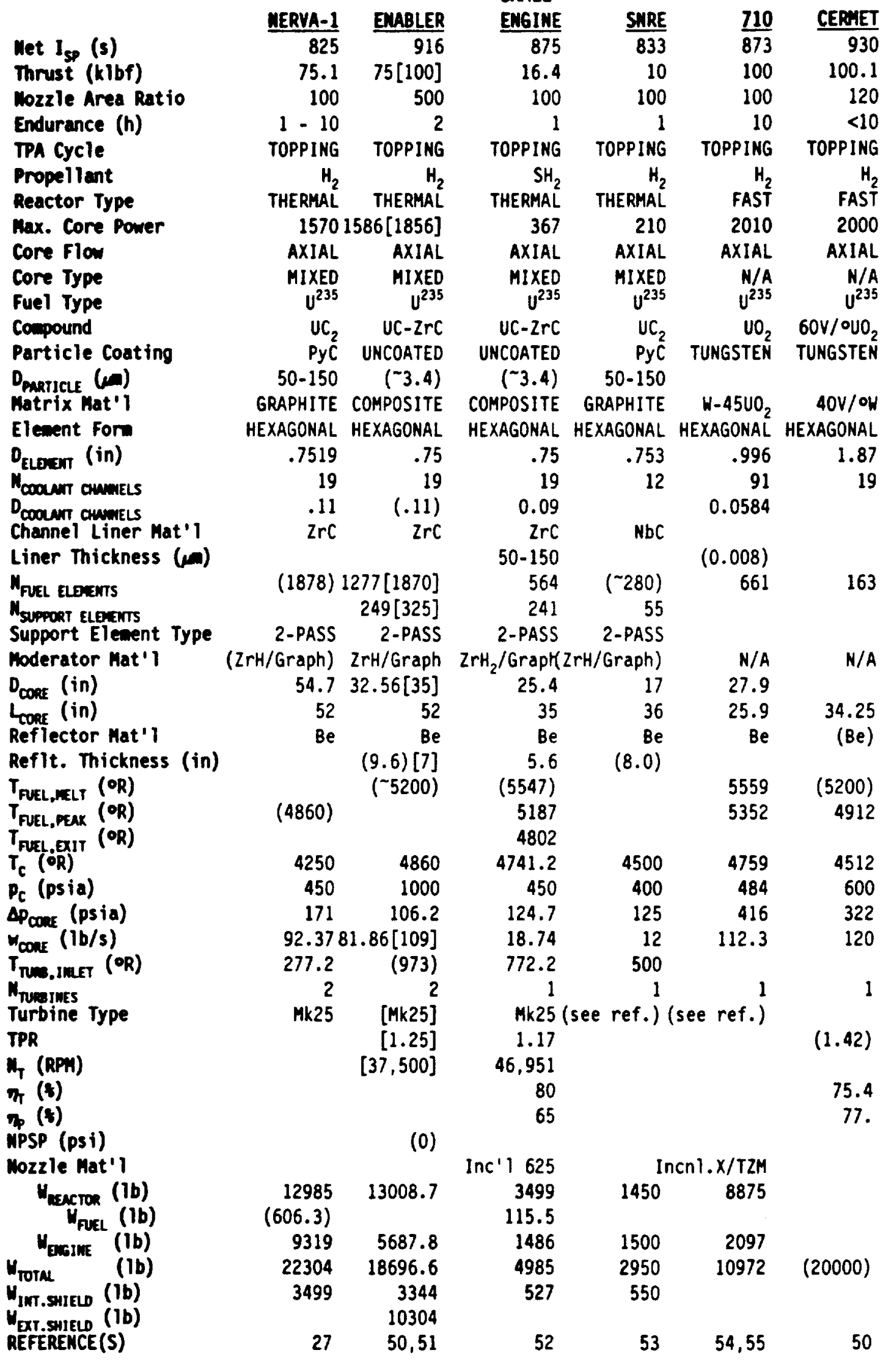




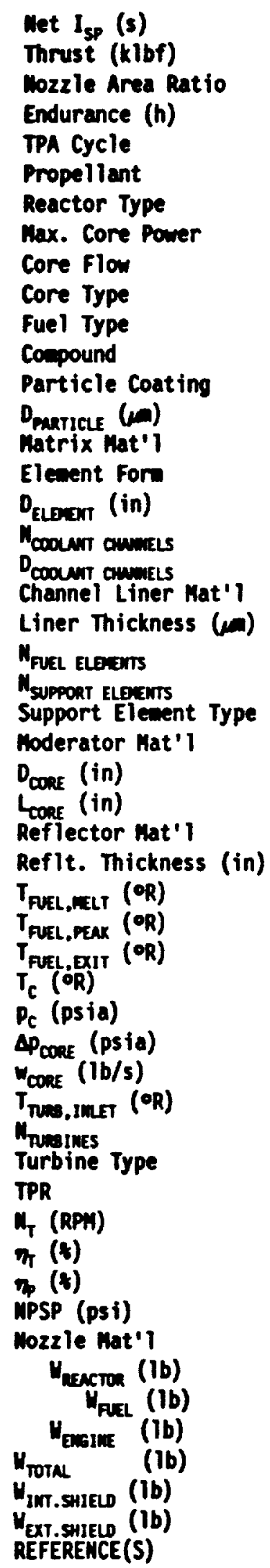

\begin{tabular}{|c|c|c|c|c|c|}
\hline PBR 1 & PQR 12 & PeBR & LPNTR 11 & LPNTR 12 & $\begin{array}{l}\text { MARRS } \\
\text { UIRE CORE }\end{array}$ \\
\hline 971 & 780 & 1000 & 1075 & 1050 & 930 \\
\hline \multirow[t]{3}{*}{75} & 7.4 & 70.8 & 25 & 10.7 & 205.5 \\
\hline & 125 & & 60 & 40 & 92.5 \\
\hline & .55 & & .55 & & $5-10$ \\
\hline HOT-BLEED & HOT-BLEEO & TOPPING & N/A & N/A & HOT-BLEED \\
\hline $\mathrm{H}_{2}$ & $.4 \mathrm{H}_{2} / .60$ & $\mathrm{H}_{2}$ & $\mathrm{H}_{2}$ & $\mathrm{H}_{2}$ & $\mathrm{H}_{2}$ \\
\hline THERMAL & THERMAL & FAST & THERMAL & THERMAL & FAST \\
\hline$(\sim 1945)$ & 150 & 1500 & 525 & 260 & 4400 \\
\hline RADIAL & RADIAL & \multicolumn{4}{|c|}{ RADIAL-IN RADIAL-OUT RADIAL-OUT RADIAL-OUT } \\
\hline MIXED & MIXED & N/A & HOMO & HOMO & N/A \\
\hline$u^{235}$ & $u^{235}$ & $u^{235}$ & $u^{235}$ & $u^{235}$ & $u^{235}$ \\
\hline$U C_{2}$ & $U C-2 r C$ & UC-TaC & UC-ZrC & $u c-2 r C$ & UN \\
\hline $\mathrm{PyC} / \mathrm{ZrC}$ & PyC/ZrC & $\mathrm{PyC} / \mathrm{TaC}$ & & & TUNGSTEN \\
\hline 500 & 500 & 500 & 1000 & 1000 & 100 \\
\hline NONE & NONE & NONE & NONE & NONE & TUNGSTEN \\
\hline PARTICLE & PARTICLE & PELLET & BEADS & BEADS & WIRE \\
\hline & & 0.394 & & & 0.035 \\
\hline N/A & $N / A$ & N/A & N/A & N/A & $N / A$ \\
\hline$N / A$ & N/A & N/A & N/A & N/A & N/A \\
\hline N/A & N/A & $\operatorname{ZrC}$ & $N / A$ & $N / A$ & N/A \\
\hline \multirow[t]{12}{*}{$N / A$} & \multirow[t]{4}{*}{ N/A } & 0.5 & $N / A$ & $N / A$ & N/A \\
\hline & & & & & N/A \\
\hline & & & & & $N / A$ \\
\hline & & N/A & N/A & $N / A$ & N/A \\
\hline & \multirow[t]{3}{*}{ Be } & & $\mathrm{Be}+\mathrm{ZrH}$ & $\mathrm{Be}+\mathrm{ZrH}$ & N/A \\
\hline & & 31.5 & 19.68 & 27.6 & 24 \\
\hline & & 51.28 & $N / A$ & & 32 \\
\hline & Be & $\mathrm{BeO}$ & $B e$ & Be & $\mathrm{Be}$ \\
\hline & \multirow{4}{*}{10.2} & & & 3.94 & 4.0 \\
\hline & & $<6606$ & 6660 & 6660 & 6606 \\
\hline & & 5580 & & 6545 & 5580 \\
\hline & & 5400 & 5760 & 5760 & \\
\hline 5760 & 4950 & 5400 & 5760 & 5760 & 5400 \\
\hline \multirow[t]{2}{*}{1000} & 896 & & 10 & 15 & \\
\hline & (45) & & 20 & 20 & \\
\hline 77.24 & 8.4 & 70.54 & 23.2 & 10.5 & 70.54 \\
\hline 2800 & 2500 & & $N / A$ & N/A & \\
\hline \multirow[t]{2}{*}{1} & 1 & & N/A & N/A & \\
\hline & & & $N / A$ & $N / A$ & \\
\hline
\end{tabular}

80.

70.

$\mathrm{C} / \mathrm{C}$

2250

$1323 \quad$ (2204)

1500

3750

(1929)

4133

8818

N/A

50

56

57,50
1527

$154.3 \quad(88.2)$

2528

$4360 \quad 4056$

58

50

(2204) 


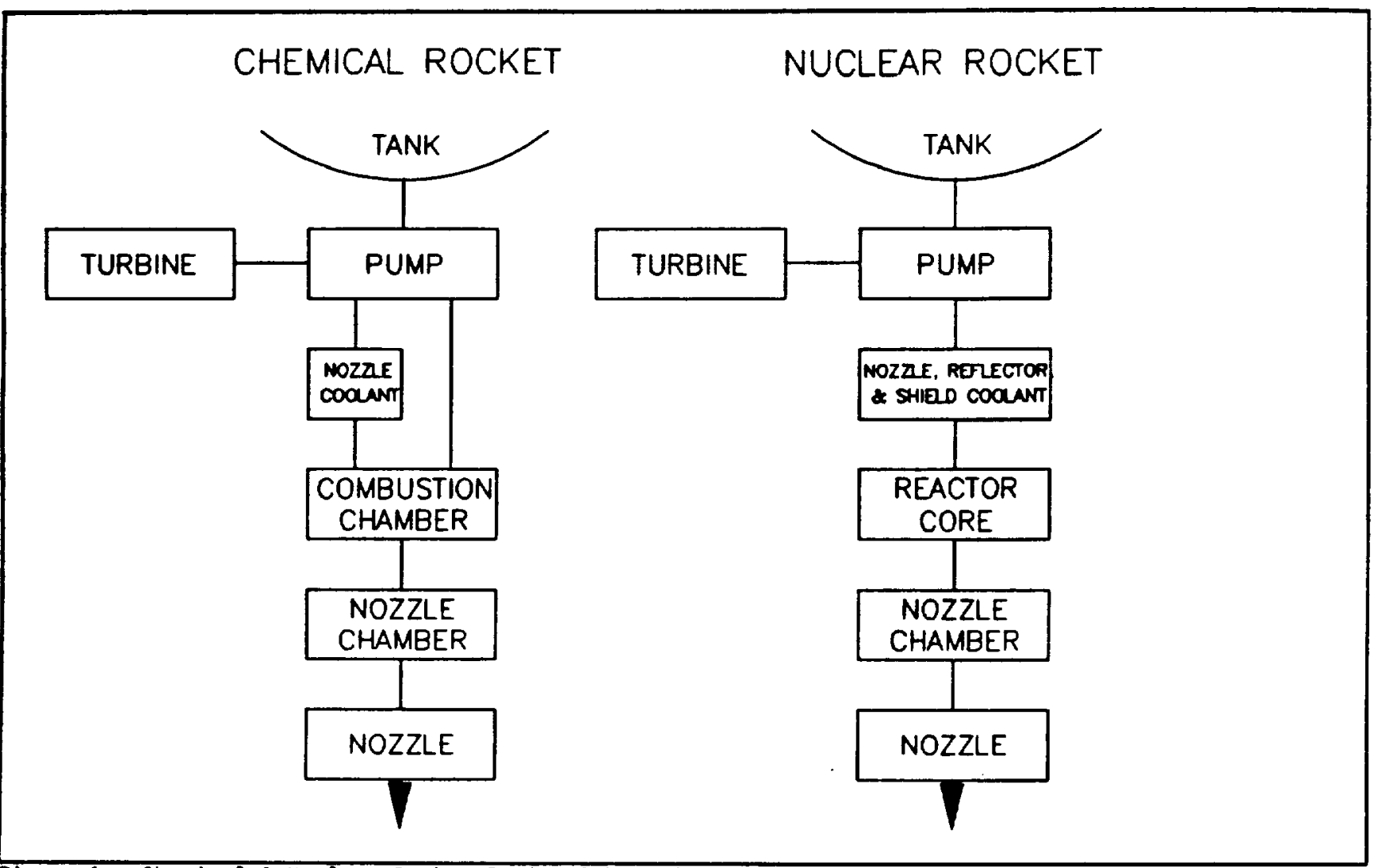

Figure 1 - Chemical \& Nuclear Rocket Engine Schematics.

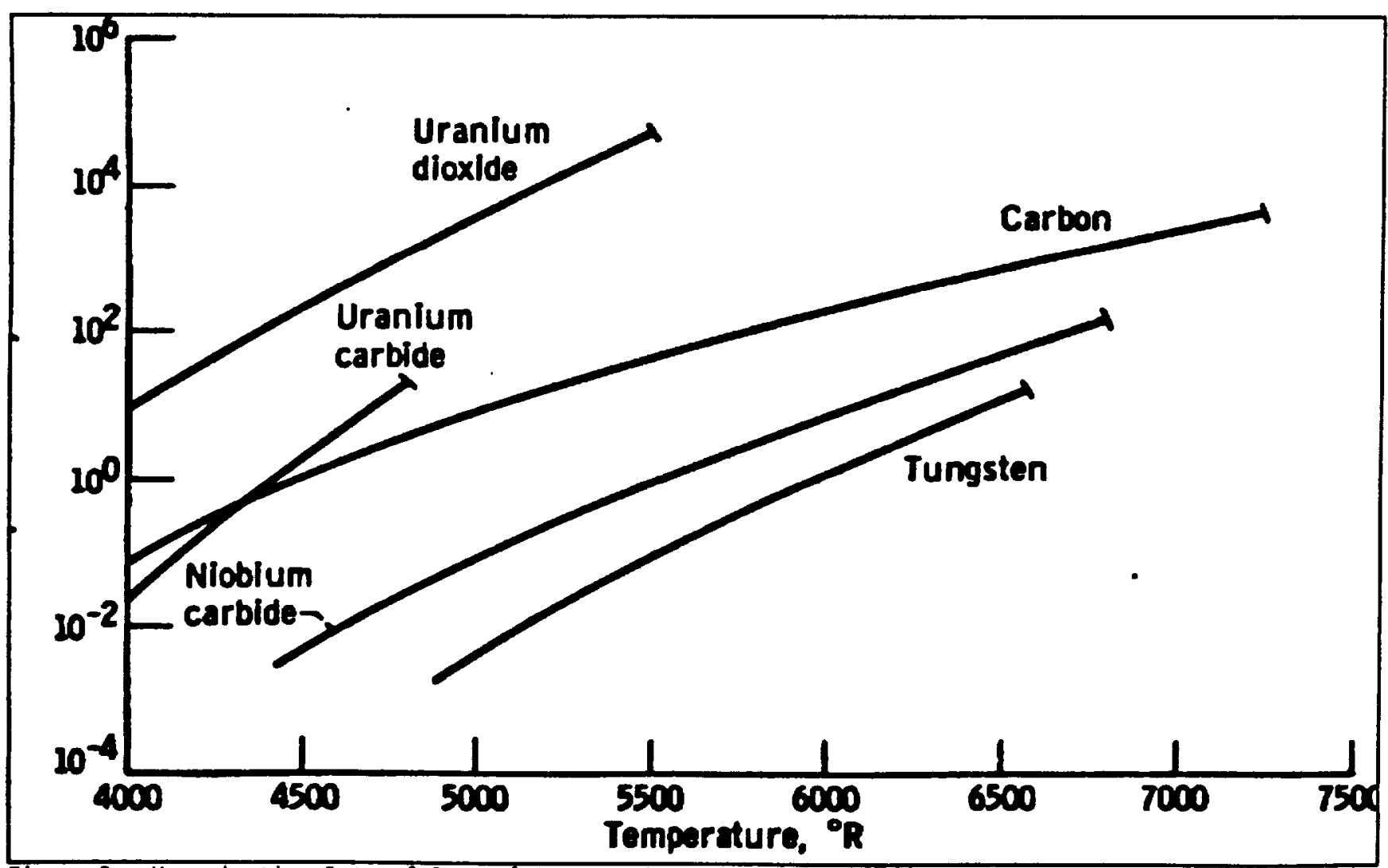

Figure 2 - Vaporization Rate of Several Reactor Core Materials. 


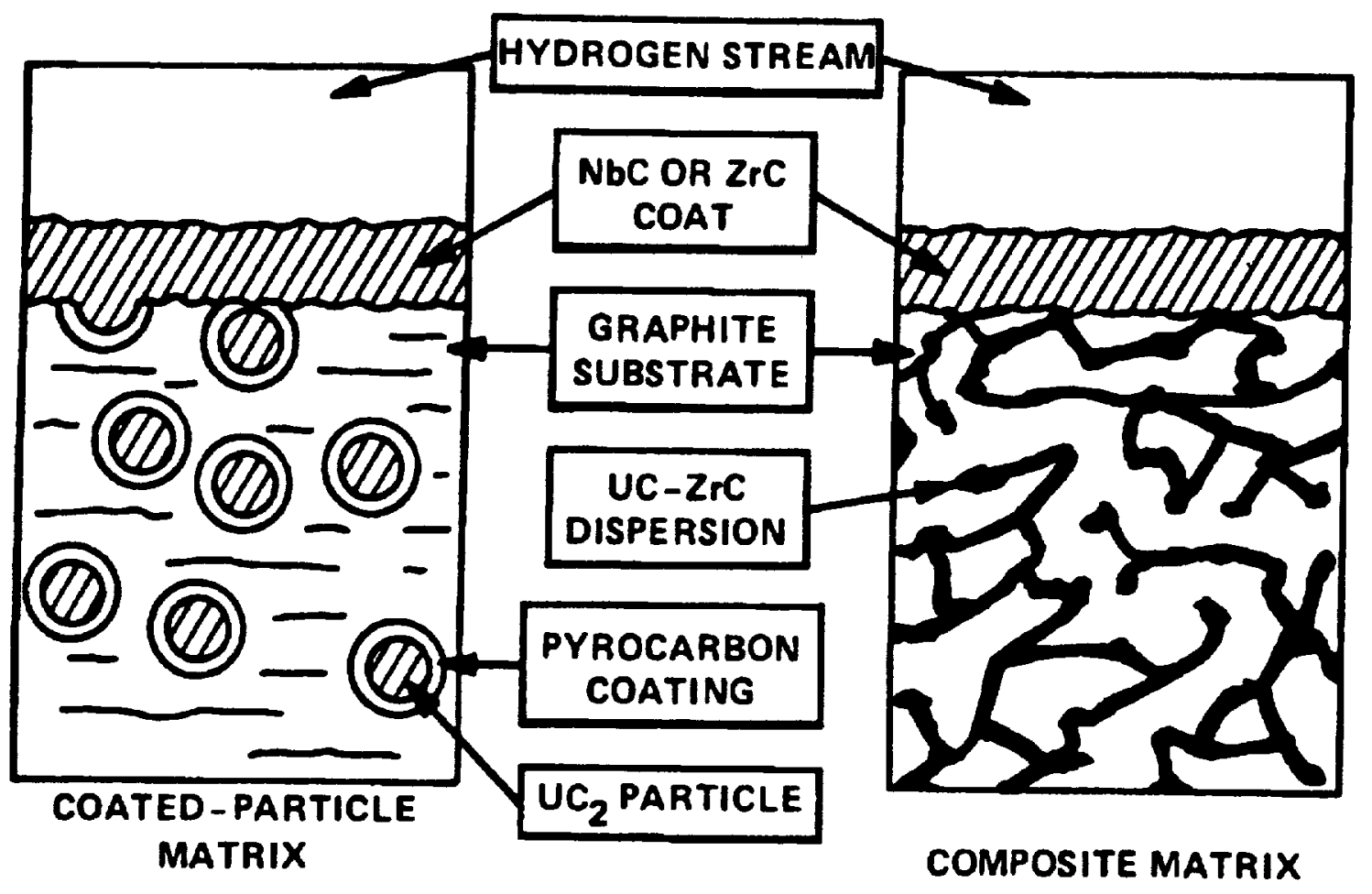

Figure 3 - Comparison of Graphite-Coated Particle Matrix Structure to Graphite-Carbide Composite.

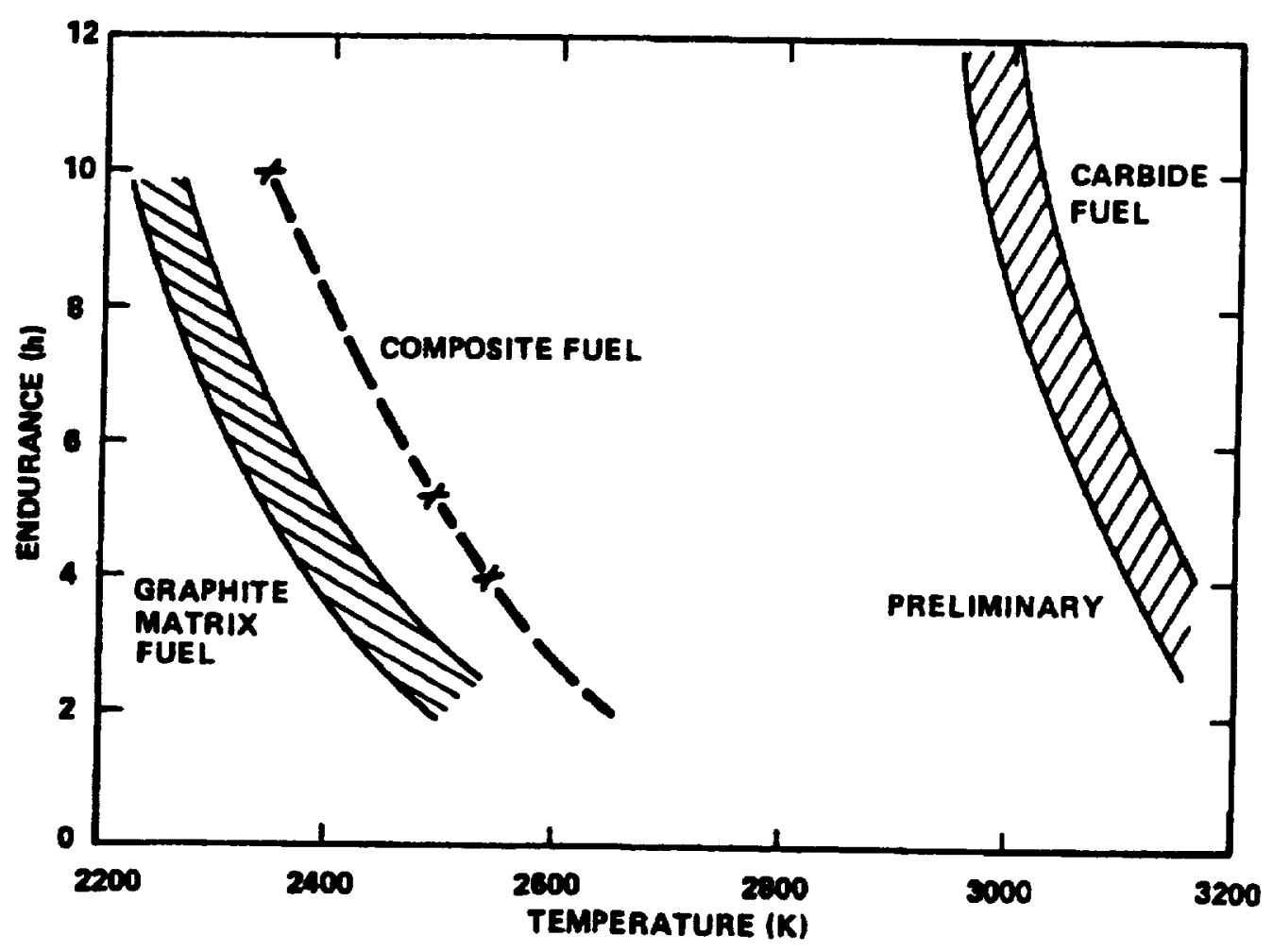

Figure 4 - Comparison of Projected Endurance Level. 


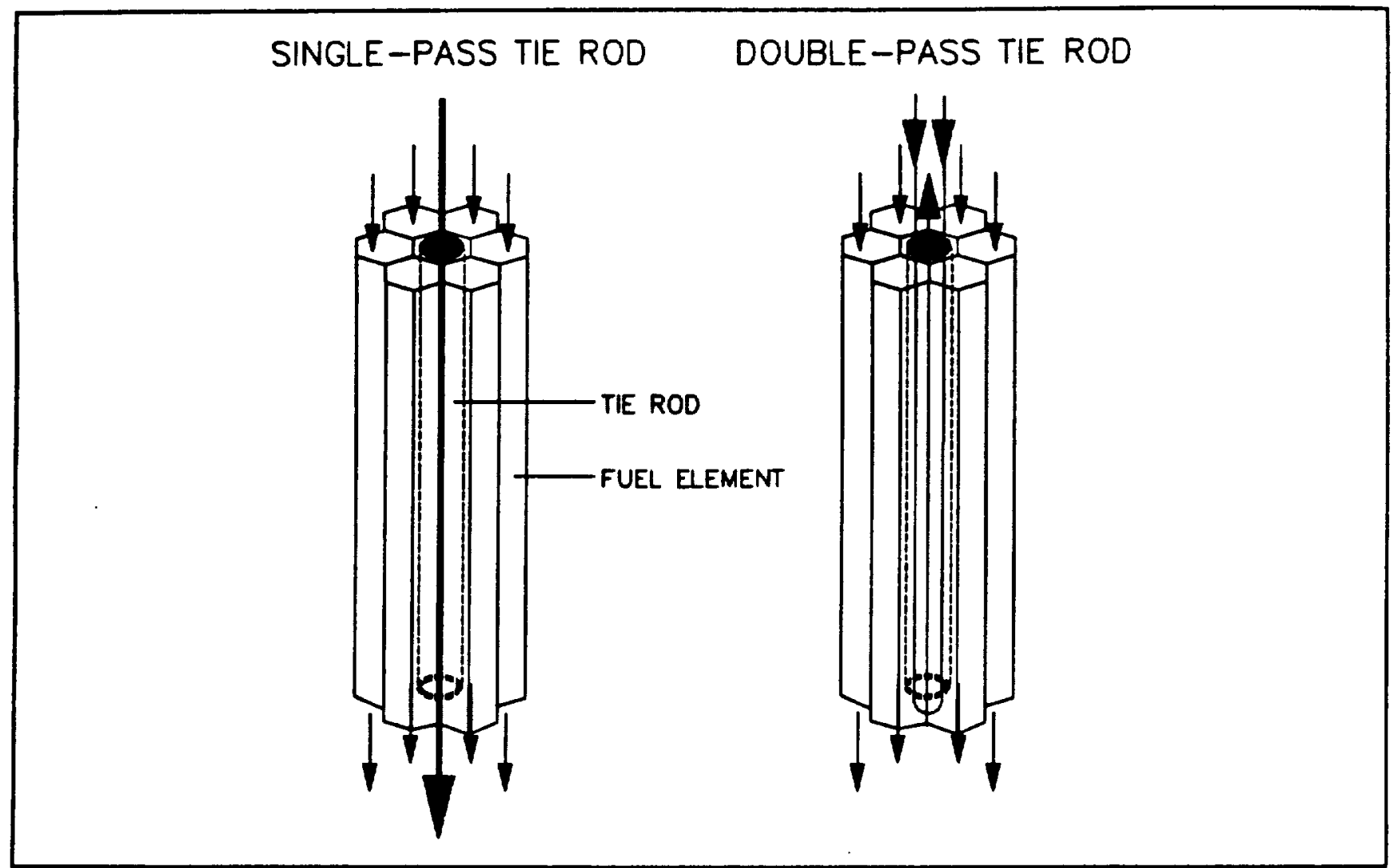

Figure 5 - Single and Two Pass Tie-Rod flow Schematics.

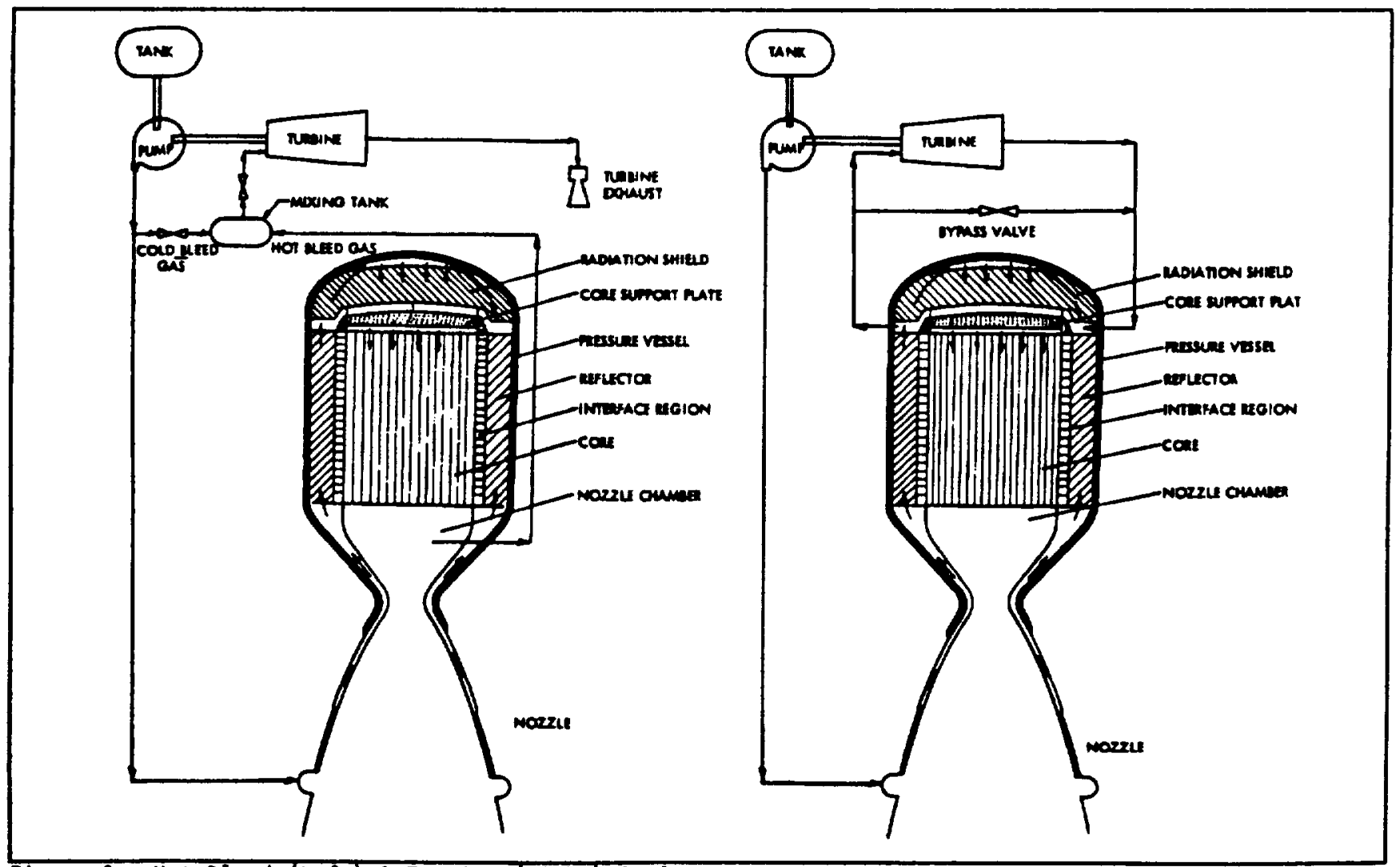

Figure 6 - Hot-Bleed (Left) \& Topping (Right) Cycle. 


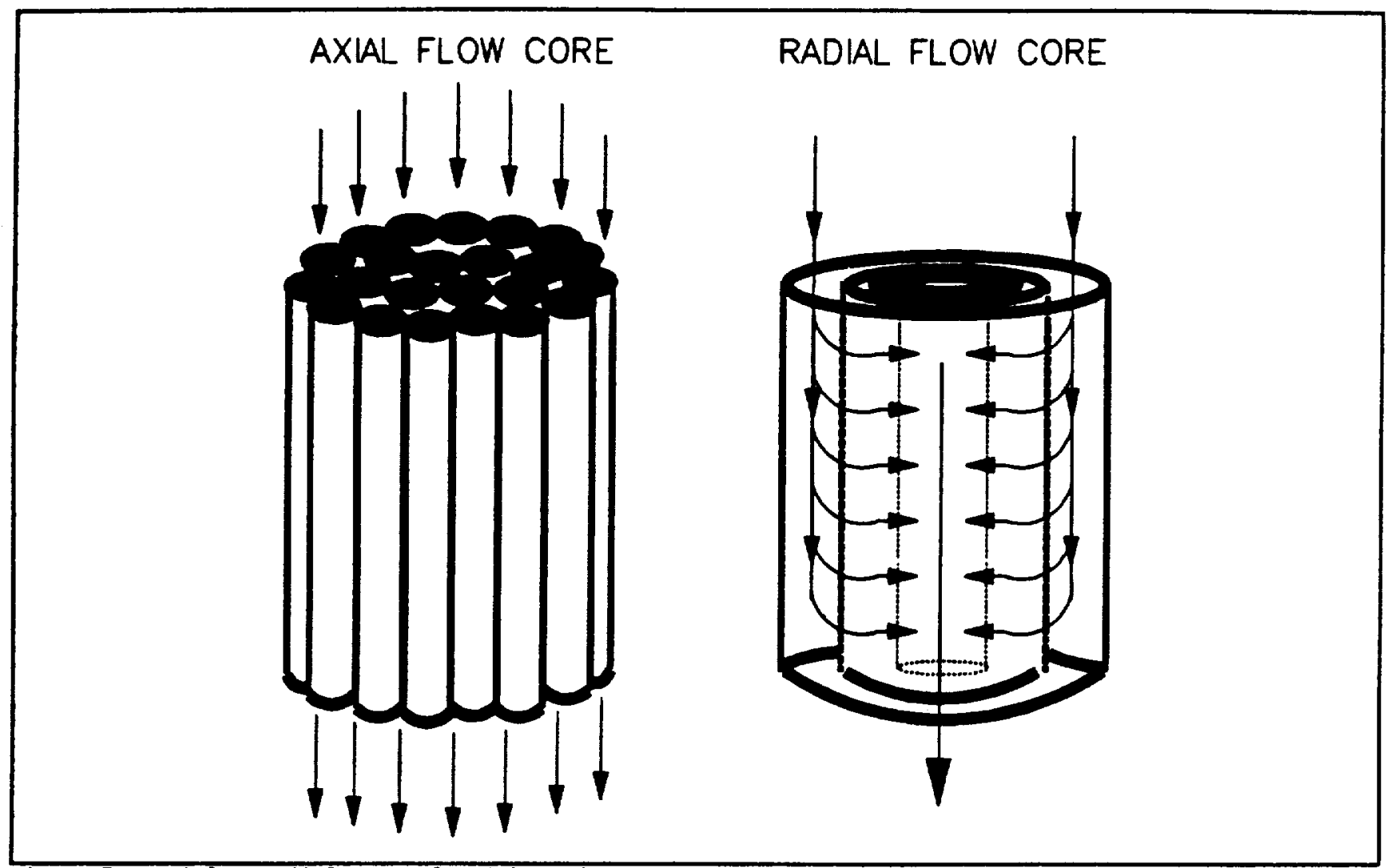

Figure 7 - Axial \& Radial Core Flow Schematics.

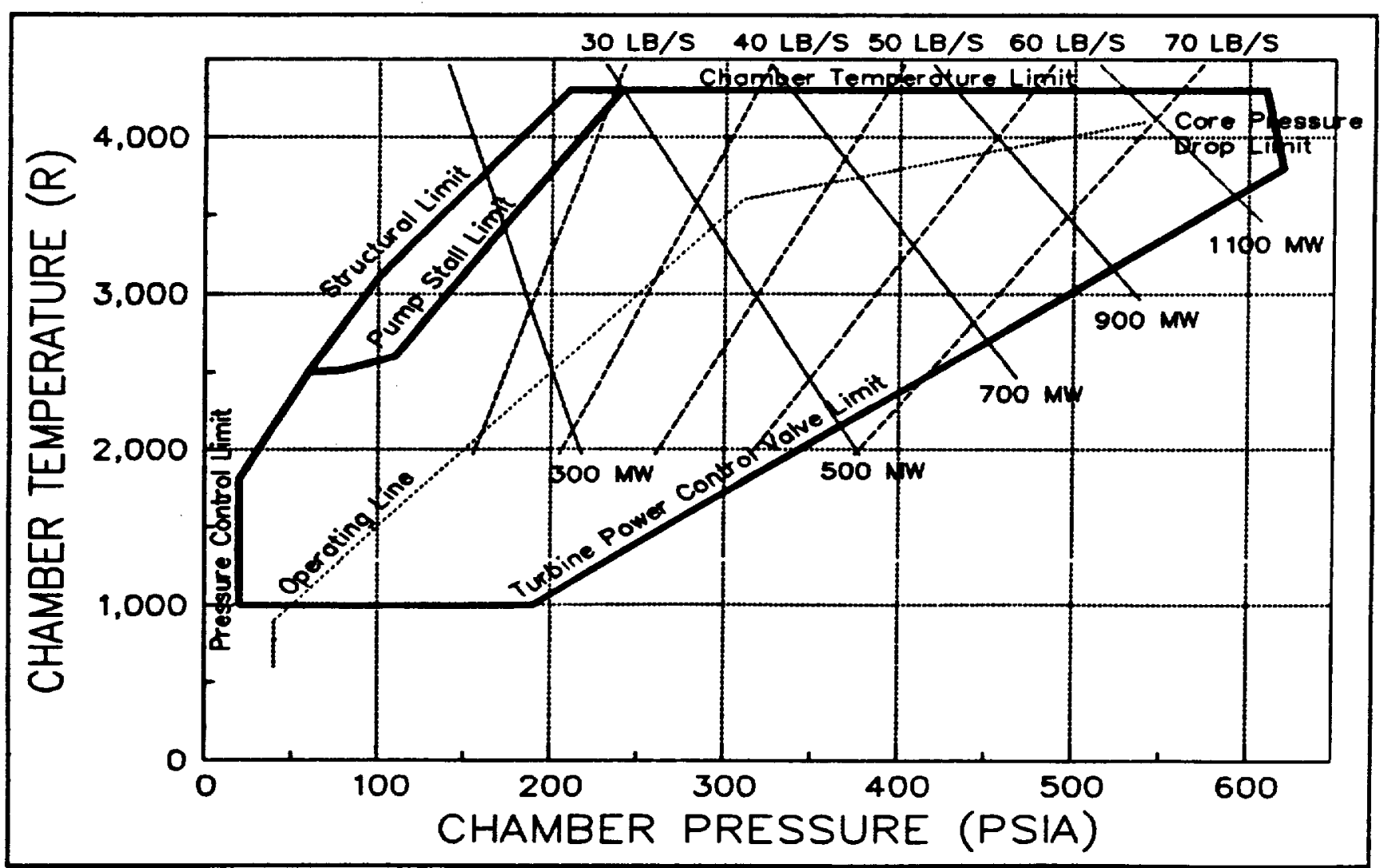

Figure 8 - XE-PRIHE Operating Map. 


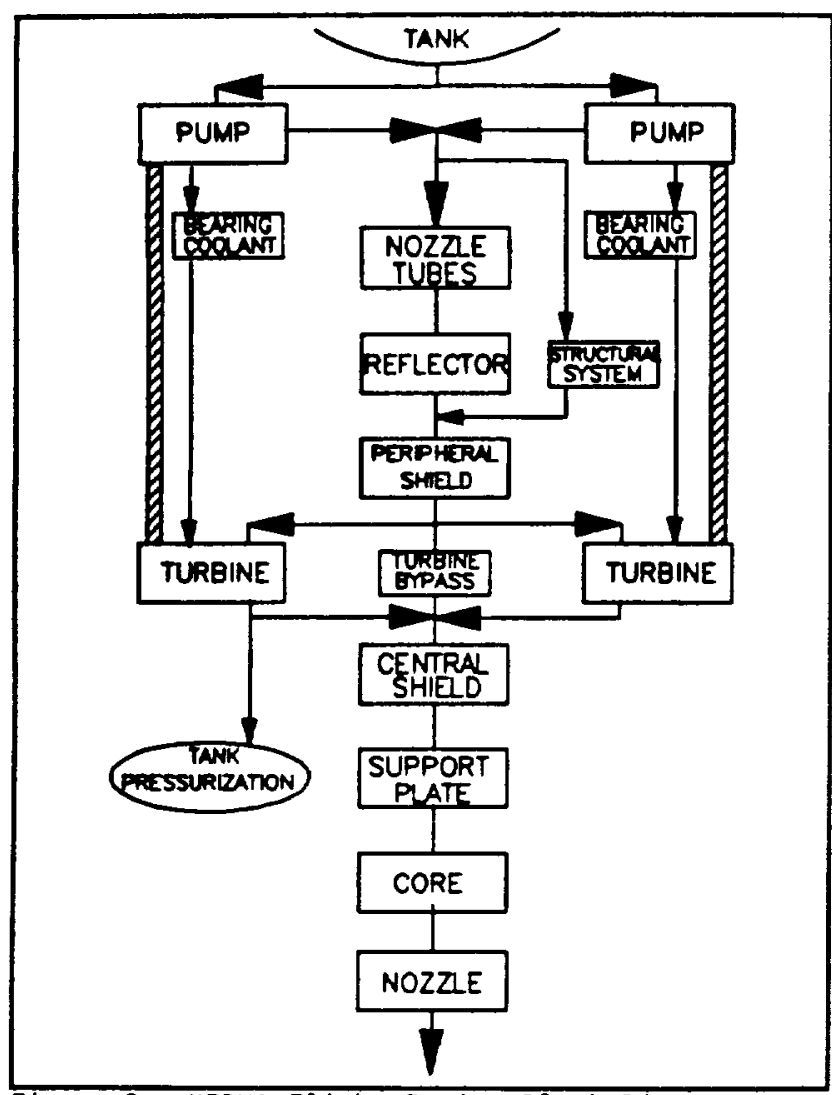

Figure 9 - NERVA Flight Engine Block Diagram.

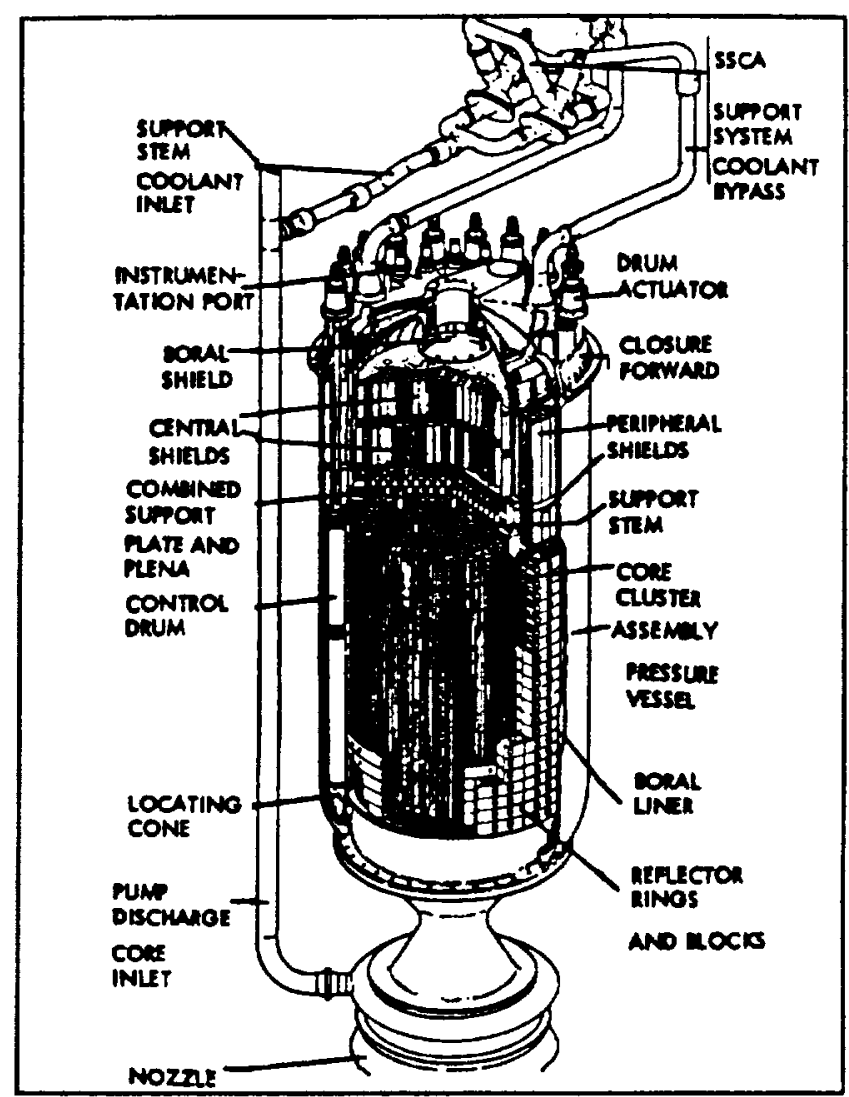

Figure 10 - NERVA Flight Engine Nuclear Subsystem

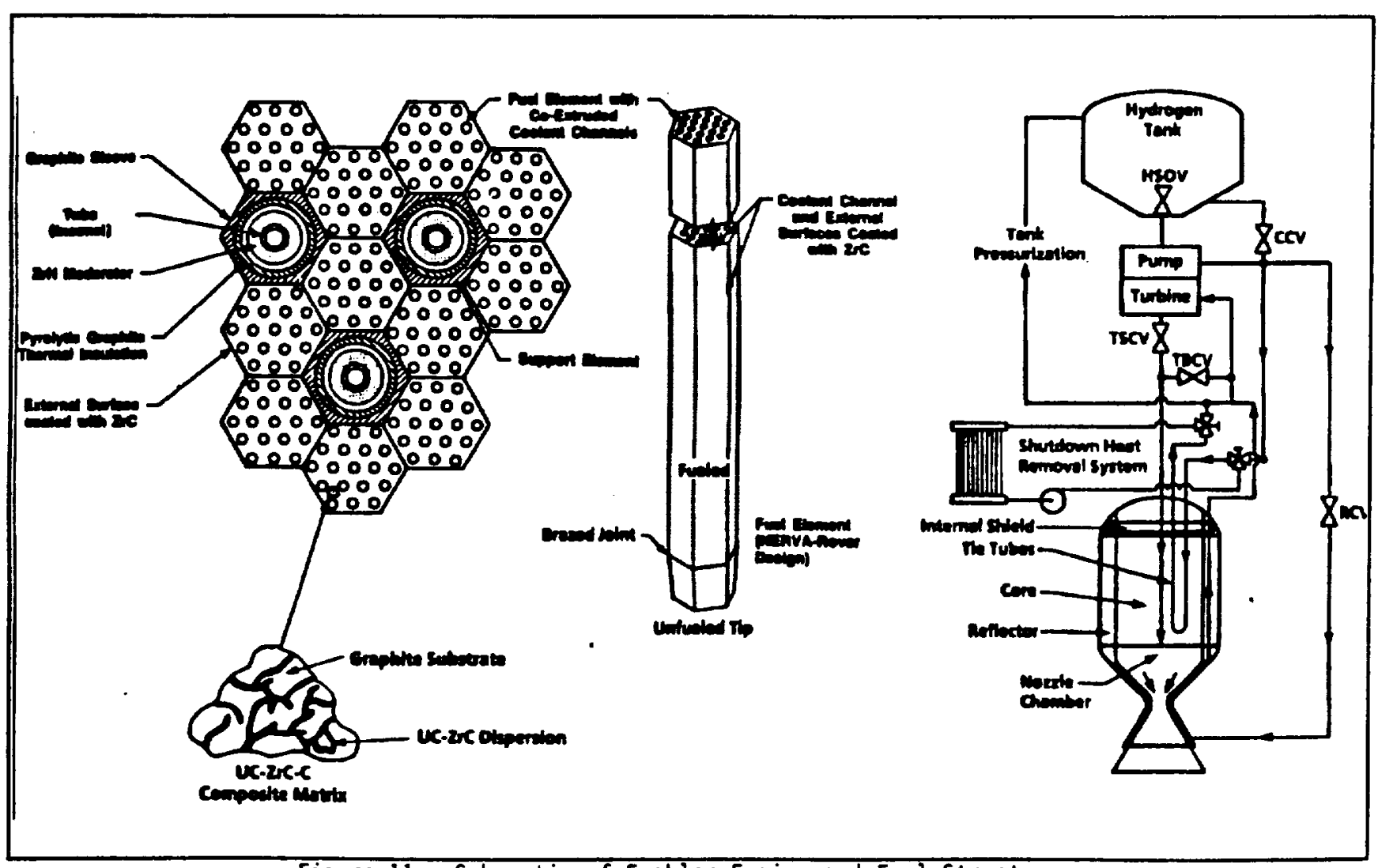

Figure 11 - Schematic of Enabler Engine and Fuel Structure. 




Figure 12 - Schmatic of Small Engine and Fuel Element Sturcture.

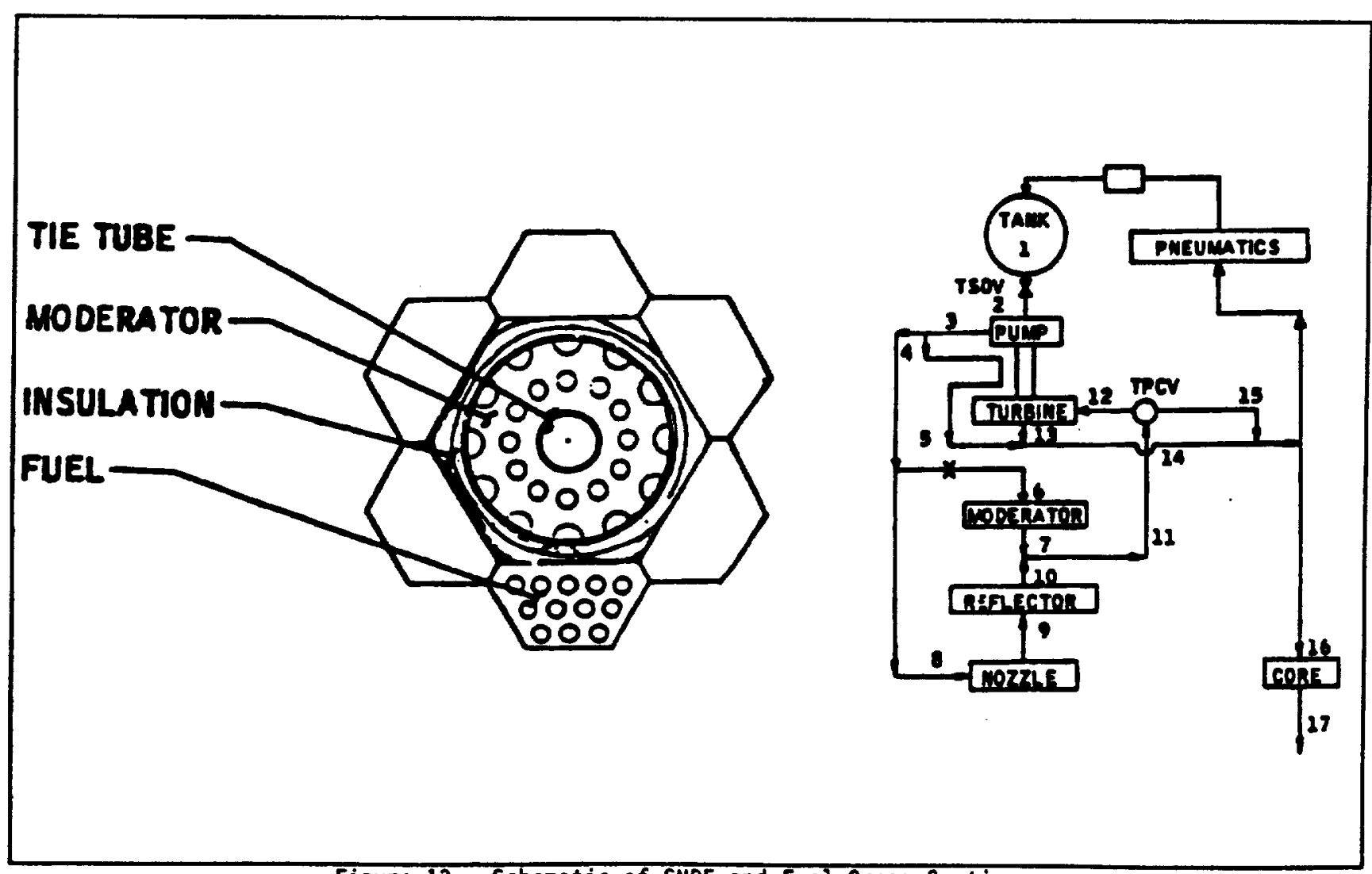

Figure 13 - Schematic of SNRE and Fuel Cross-section. 


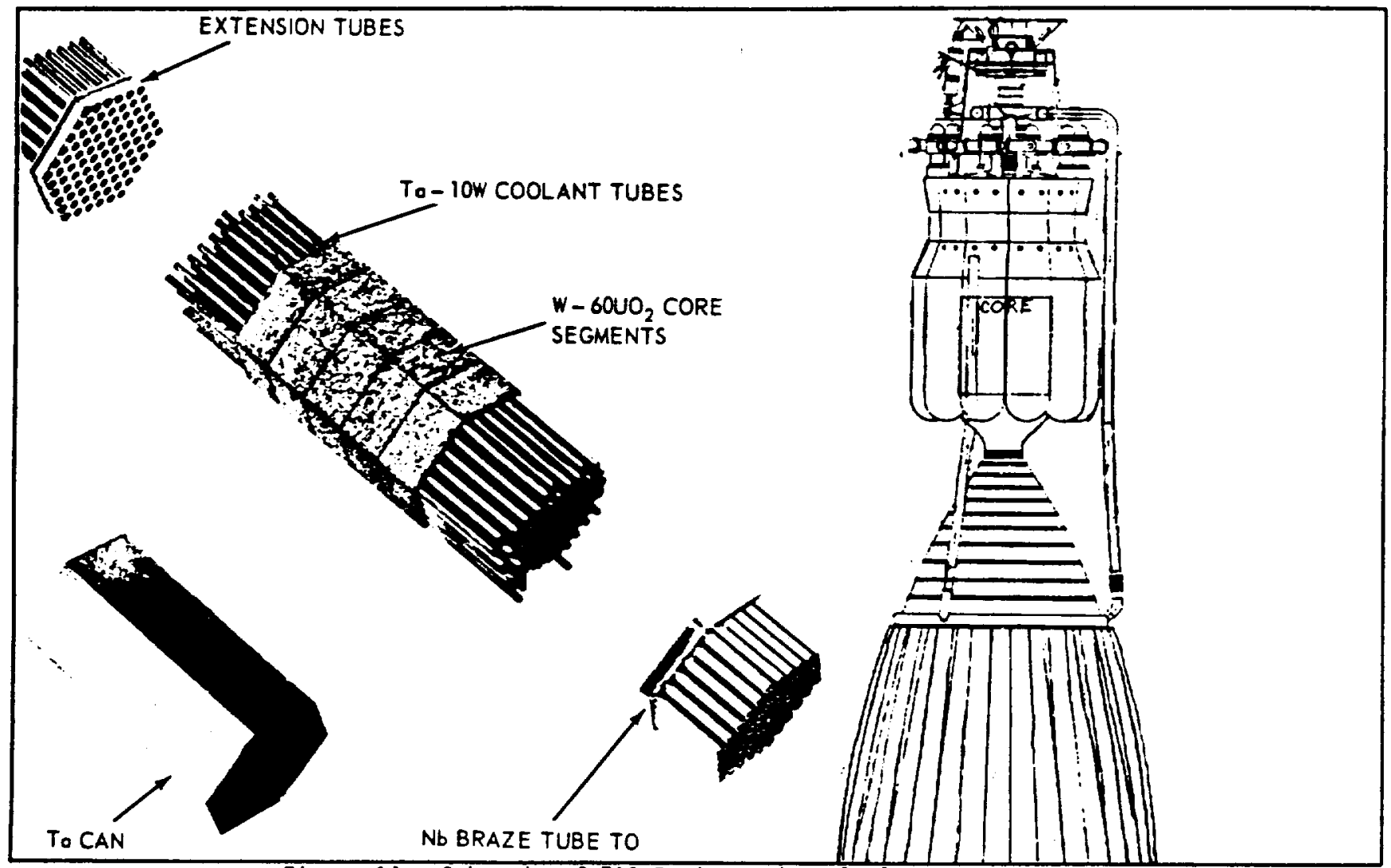

Figure 14 - Schmatic of 710 Engine and Fuel Element Structure.

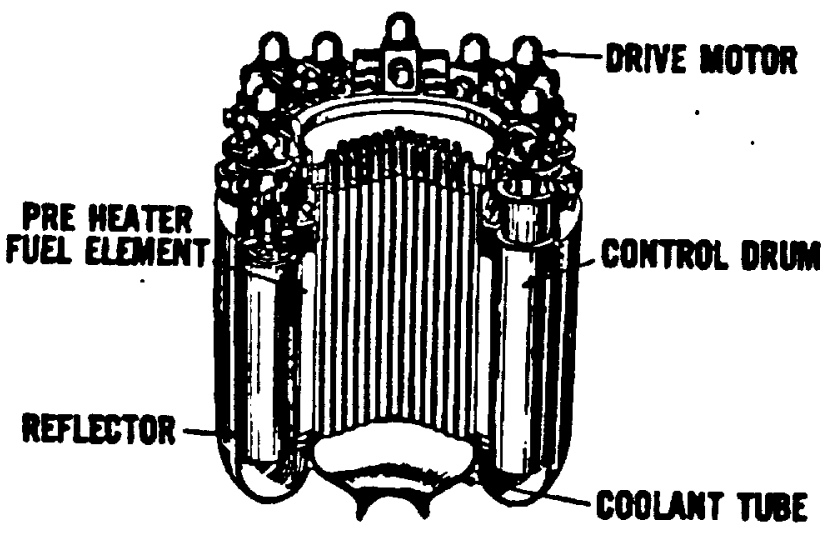

REACTOR INTERNALS
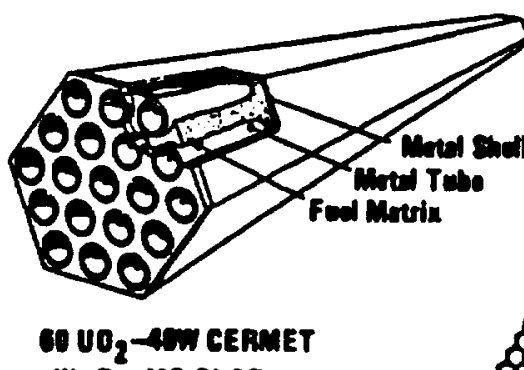

w-Pr-No CLAO

Figure 15 - Schmatic of Cermet Engine and Fuel Element. 


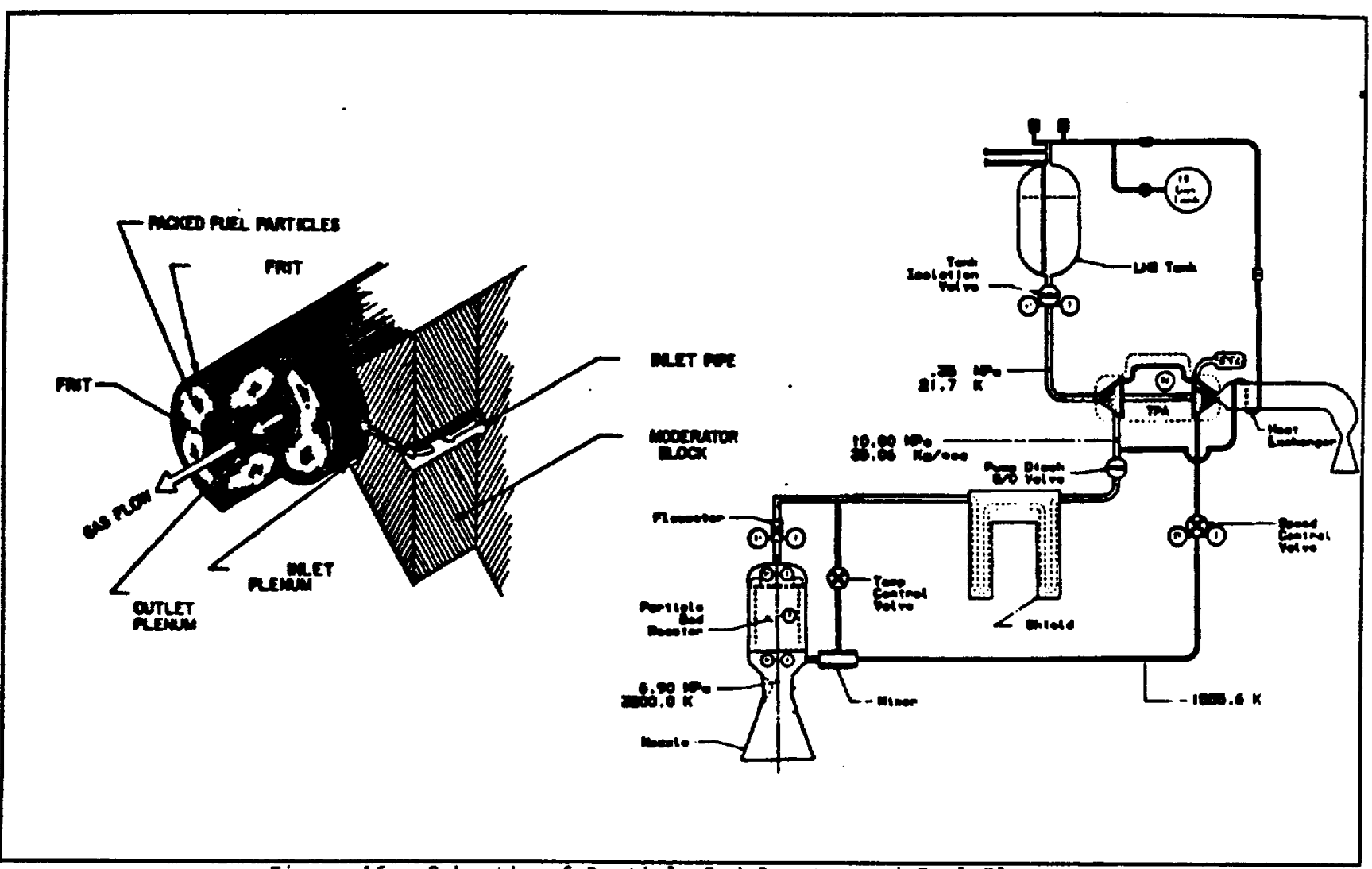

Figure 16 - Schmatic of Particle Bed Reactor and Fuel Element.

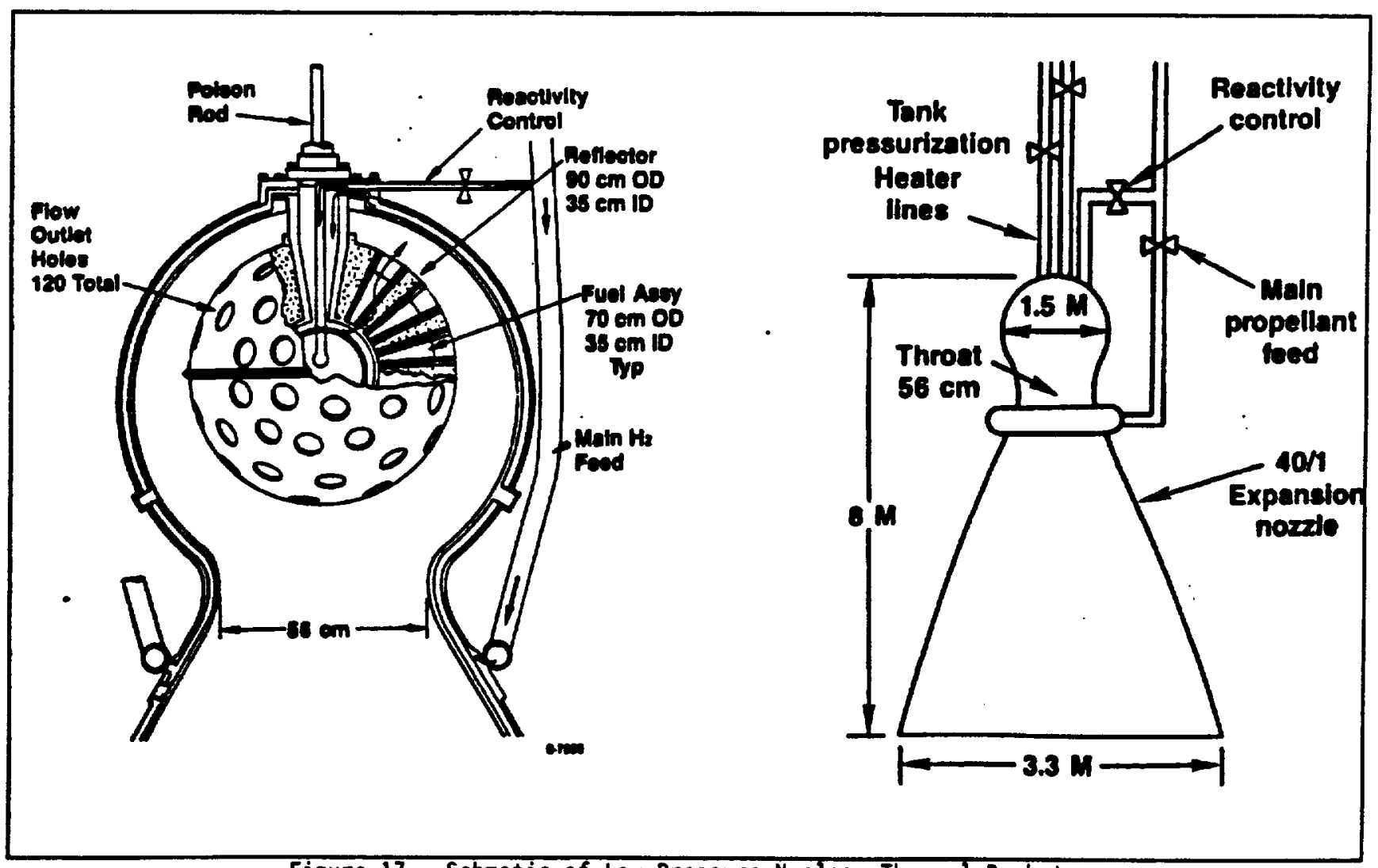

Figure 17 - Schmatic of Low Pressure Nuclear Thermal Rocket. 


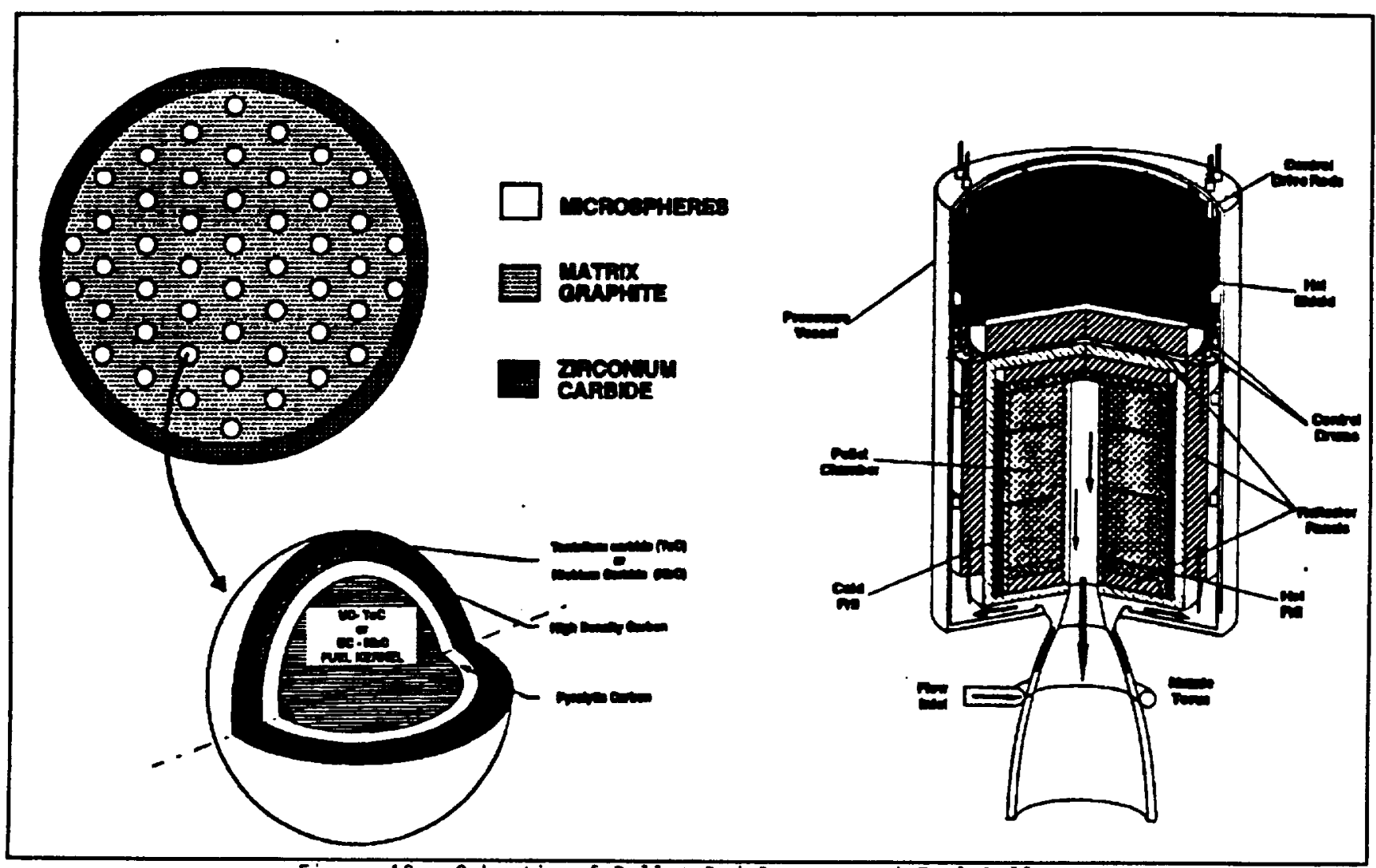

Figure 18 - Schmatic of Pellet Bed Reactor and Fuel Pellet.

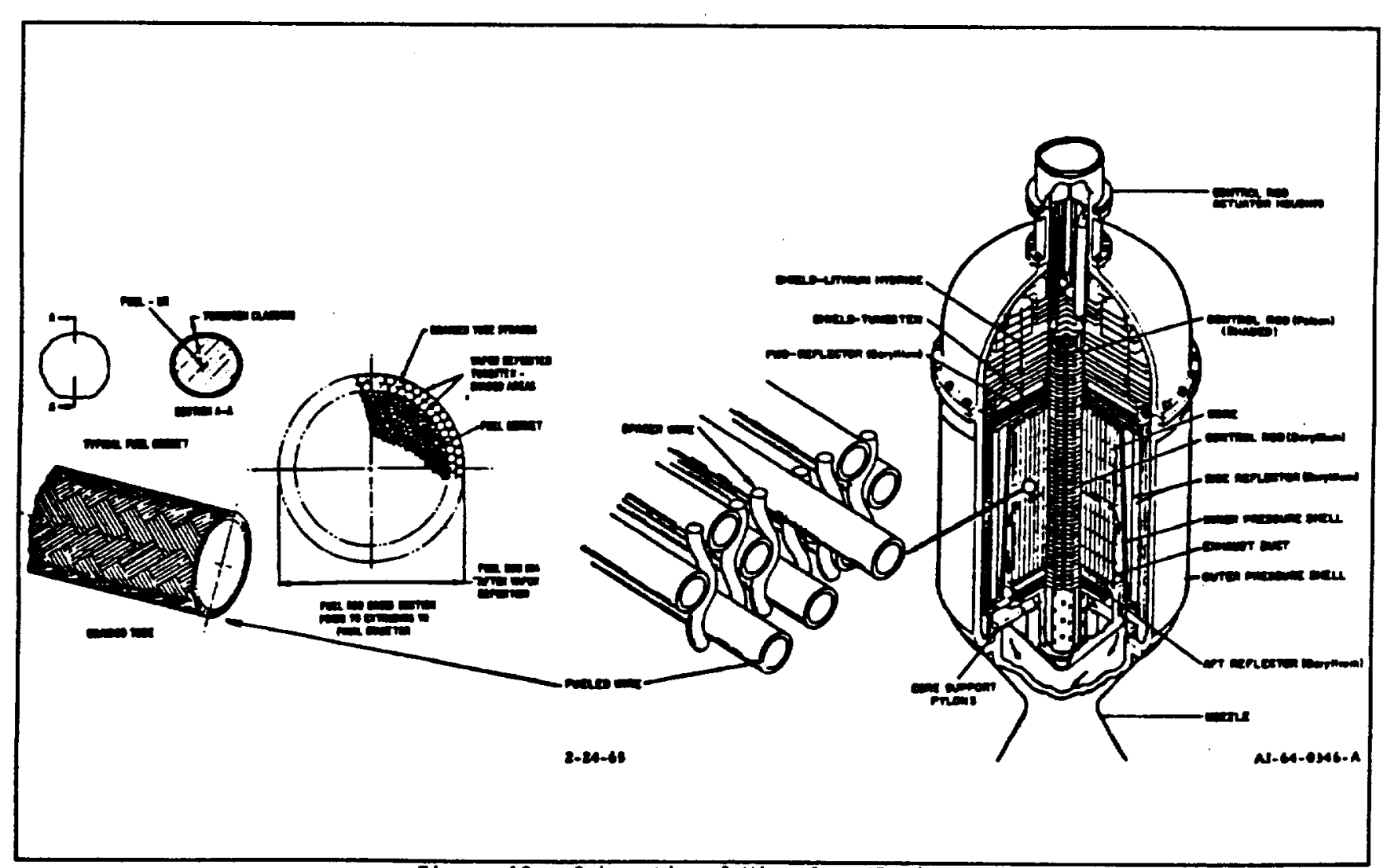

Figure 19 - Schematic of Wire Core Engine. 


\section{REFERENCES}

1. Borowski, Stanley K.: Nuclear Propulsion - A Vital Technology for the Exploration of Mars and the Pianets Beyond. NASA TM 101354, July 1987.

2. Bogart, Donald; Lantz, Edward: Nuclear Physics of Solid Core Gas-Cooled Rocket Propulsion Reactors. MASA SP-20, December 1962.

3. Kirk, M.L.; Hopkins, J.R.; Sapir, L.J.: Study of a Heterogeneous Reactor For Rocket Propulsion. LAMS2930, October 1963.

4. Anon.: 710 High-Temperature Gas Reactor Program Sumary Report. General Electric Report GEMP-600, Volumes $1-V I, 1970$.

5. Arnold, D.J.; Bilbin, K.; Mouradian, E.M.; Nachman, J.F.; Oliver, D.G.; Rosenberg, H.N.; Thomson, H.B.: Metallic Annular Rocket Reactor System (MARRS) Design Study. Atomics International Report AI-65-34, May 1965.

6. Finseth, J.L.: Overview of Rover Engine Tests: Final Report. Contract NAS 8-37814, February 1991.

7. Harvego, E.A.; Ransthaler, J.H.; Parks, D.L.; Reeds, H.C.; Gillies, B.B.; Whitbeck, J.F.: Requirements and Cost Considerations for a Combined Space Nuclear Reactor Test Facility. Fourth Symposium on Space Nuclear Power Systems, Albuquerque, New Mexico, January 12-16, 1987.

8. Bohl, R.; Hanson, D.; Edskuty, F.: Planning for Ground Testing of Nuclear Rocket Engines With Todays Environmental Awareness. AlAA paper 90-2517, July 1990.

9. Anon.: Future NASA Space Programs. U.S. Government Printing Office, Washington, D.C., Hearing Before the Committee on Aeronautical and Space Sciences, United States Senate, 91st Congress, First Session, August 5, 1969 (N69-36050).

10. Wetch, Joesph R.: Development of Nuclear Rocket Engines in the USSR. Presented at the NASA-AIAA Sympos ium on Advanced SEI Technologies, September 4-6, 1991, Cleveland, Ohio.

11. Merkle, T.C.; Reynolds, H.L.: The Pluto Program. University of California Lawrence Radiation Laboratory, Livermore, California, UCRL-6941, June 1962.

12. Hadley, James H.: The TORY II-A Reactor Tests, Final Report. UCRL-7249, May 1963.

13. Reynolds, Harry L.: TORY II-C Reactor Test Report. UCRL-12069, October 1964.

14. Koenig, D.R.: Experience Gained from the Space Nuclear Rocket Program (ROVER). Los Almos National Laboratory, LA-10062-H, May 1986.

15. MacMillan, D.P.; Driesner, A.R.: Post-Mortem Examination of KIHI-A. LA-2430, July 1960.

16. Brown, D.H.: KIHI-A Prime Test Series - Part I: Final Report on the KIHI-A Prime Full Power Run. LAMS-2492, December 1960.

17. York, D.A.: Sumary of KIHI-A3 Disassembiy and Post-Mortem. LA-2592, July 1961.

18. Spence, R.W.: A Preliminary Report of the KIWI-A Tests. LAMS-2483, February 1961.

19. Brown, D.H.; Cerni, S.: Final Report on the KIWI-BIA Full-Power Run. LAMS-2708, April 1962.

20. Brown, D.H.: Final Test Report KIWI-B1B Reactor Experiment. LA-3131-MS. November 1963.

21. Elder, N.: Preliminary Report KIHI-B4D Full Power Run. LA-3120-MS, August 1964.

22. Zeigner, V.L.: Survey Description of the Design and Testing of KIWI-B4E Propulsion Reactor. LA-3311MS, May 1965.

23. Chezen, C.G;: Hansen, G.E.; Helmick, H.H.; Seale, R.L.: The Los Alamos Coupled Reactor Experience. LA-3494, January 1967.

24. Elder, Ni Preliminary Report Phoebes-1A. LA-3375-MS, September 1965.

25. Anon.: Phoebes-IB Disassembly Post-Mortem Results. LA-3829, September 1968.

26. Anon.: Phoebes-2A Preliminary Report. LA-4159-MS, January 1969.

27. Anon.: Peewee-1 Reactor Test Report. LA-4217-MS, August 1969.

28. Lyon, Luther L.: Performance of $(U, Z r) C$-Graphite (Composite) and of $(U, Z r) C$ (Carbide) Fuel Elements in the Nuclear Furnace 1 Test Reactor. LA-5398-MS, September 1973.

29. Anon.: MERVA Program NRX-A2 Test Final Report. WANL-TNR-193, 1965.

30. Anon.: NRX-A3 Final Report. HANL-TNR-210, 1965. 
31. Anon.: MRX/EST Reactor Test Analysis Report. HANL-TNR-216, 1966.

32. Anon.: MRX-A5 Final Report. HANL-THR-220, 1967.

33. Anon.: MRX-A6 final Report. HANL-TNR-224, January 1969.

34. Anon.: XE-Prime Engine Final Report. AGC RN-S-0510, 1970.

35. Anon.: Aerospace Nuclear Applications, Proceedings. American Nuclear Society, 1970 Topical Meeting, Huntsville, Alabama, April 1970.

36. Sanders, John C.; Heppler, Herbert J. Jr.; Hart, Clint E.: Problems in Dynamics and Control of Nuclear Rockets. NASA SP-20, December 1962.

37. Gabriel, David S.; Helms, Ira L.: Nuclear Rocket Engine Program Status - 1970. AIAA Paper 70-711, June 1970.

38. Anon.: Nuclear Safety Criteria \& Specifications for Space Nuclear Reactors. U.S. Dept. of Energy, Office of Space Huclear Power, OSNP-1, August 1982.

39. Voss, Susan S.; Dix, G.P.: A Review of the Rover Safety Program, 1959-1972. Paper Presented at the Space Nuclear Propulsion Norkshop, Los Alamos, New Mexico, December 1984.

40. Anon.: MERVA Safety Plan. Aerojet Nuclear Systems Co., Document No. S-019-22-090205-F1, September 1970.

41. Burden, D.: Nuclear Rocket Safety. IAF Paper 87-297, October 1987.

42. Harty, Richard 8.: SNAP-10A Safety Program Review. AFRPL-CP-85-002, June 1985.

43. Rice, J.H.: Nuclear Surety Requirements for Aerospace Use of Major Radioactive Sources. AFRPL-CP-85002 , June 1985.

44. McConne11, D.J.: Safety and Environmental Analys is for Space Nuclear Programs. Space Power, Vol.9, No.1, 1990.

45. Rom, Frank E.: Nuclear Rocket Propulsion. NASA TM X-1685, July 1968.

46. Gunn, S.V.: Development of Nuclear Rocket Engine Technology. AIAA 89-2386, July 1989.

47. Bohl, Richard J.; et.al.: History of Some Direct Nuclear Propulsion Development Since 1946. Presented at the Space Nuclear Power Symposium, 1987.

48. Kirk, H.L.: Nuclear Furnace-1 Test Report. LA-5189-MS, March 1973.

49. Anon.: Technical Summary of NERVA Program. HANL-TNR-230, Volume I, July 1972.

50. Nuclear Thermal Propulsion: A Joint NASA/DOE/DOD Workshop. NASA CP-XXXX, Cleveland, Ohio, July 10-12, 1990.

51. Gunn, S.V.: Design of Second Generation Nuclear Thermal Rocket Engines. AIAA Paper 90-1954, July 1990.

52. Durham, Franklin P.: Engine Definition Study. LA-5044-MS, Volumes 1-111, September 1972.

53. Anon.: SNRE: Small Nuclear Rocket Engine For Unmanned Space Probe Missions. Aerojet General Corporation Report RN-66251, August 1966.

54. Anon.: 710 High-Temperature Gas Reactor Program Summary Report. Volume II, GEMP-600, 1970.

55. Anon.: Design Criteria for a Fast Energy Spectrum Nuclear Rocket Engine. General Electric Report GEMP-250, Vol. I-VIII, December 1963.

56. Powell, J.R.; et.al.: Particle Bed Reactor Orbital Transfer Vehicle Concept. AFAL-TR-88-014, July 1988.

57. El-Genk, M.S.; Morley, N.J.; Haloulakos, V.E.: Pellet Bed Reactor For Nuclear Thermal Propelled Vehicles. Proceedings of the Eighth Symposium on Space Nuclear Power Systems, Voi. 2, January 1991.

58. Leyse, Carl F.; et. al.: Space Nuclear Propulsion - The Low Pressure Nuclear Thermal Rocket. AIAA 90-1952, July 1990.

59. Arnold, D.J.; et.al.: Metallic Annular Rocket Reactor System (MARRS) Design Study. Atomics International Repórt AI-65-34, May 1965. 


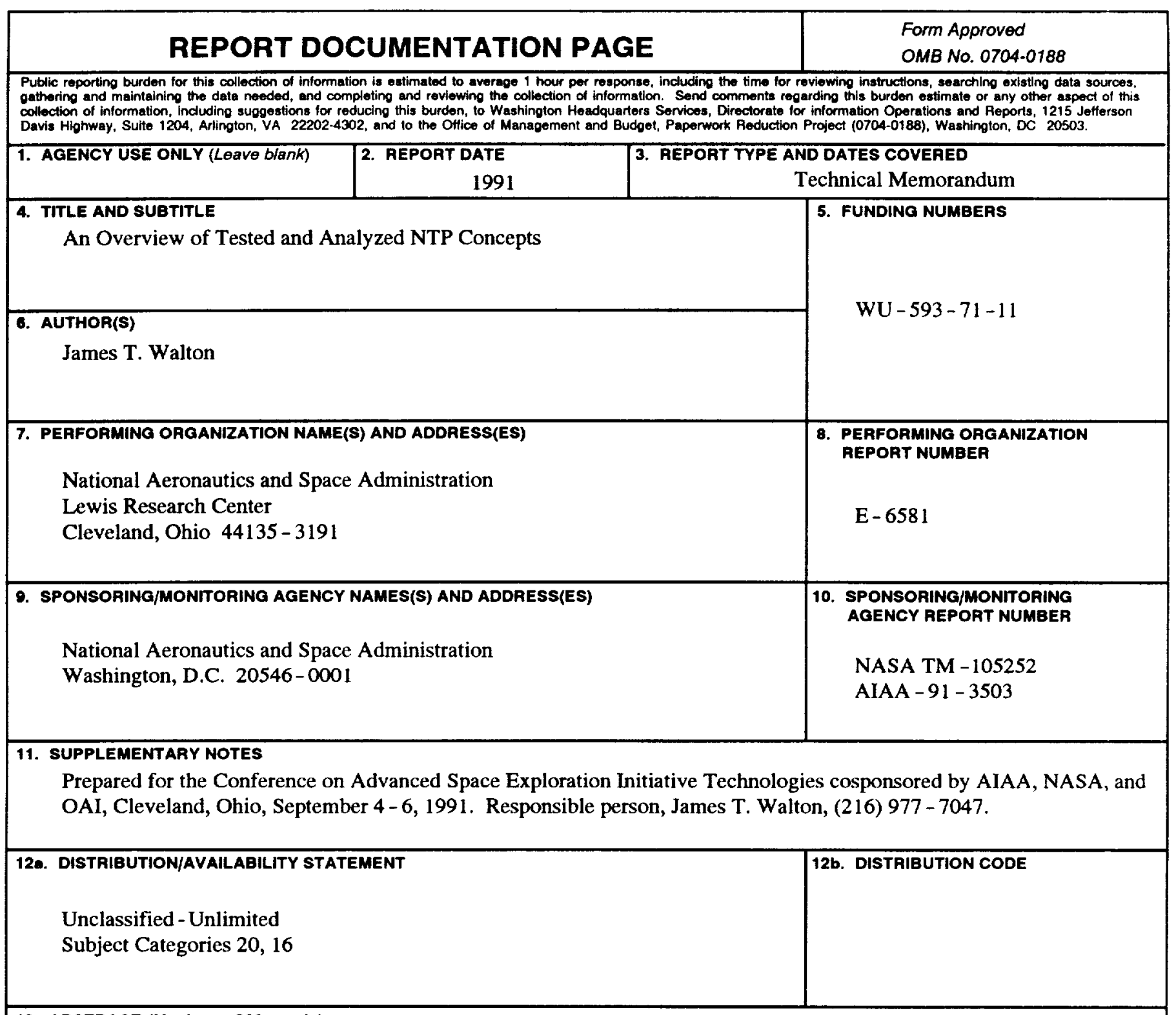

\section{ABSTRACT (Max/mum 200 words)}

If we buy into the goals of the Space Exploration Initiative (SEI) and accept that they are worthy of the hefty investment of our tax dollars, then we must begin to evaluate the technologies which enable their attainment. The main driving technology is the propulsion system; for interplanetary missions, the safest and most affordable is a Nuclear Thermal Propulsion (NTP) system. This paper presents an overview of the NTP systems which have received detailed conceptual design and, for several, testing.

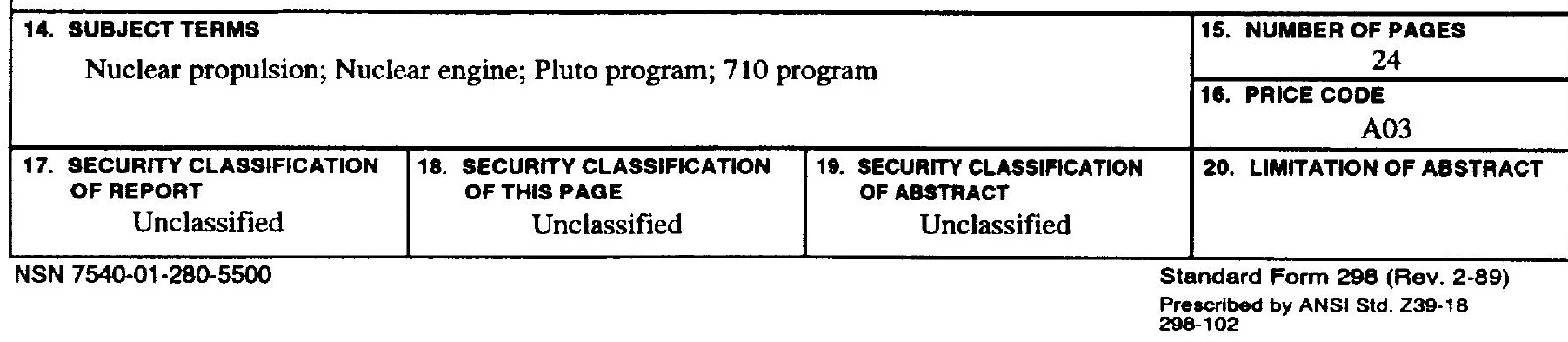

